\title{
Research Paper \\ The effectiveness of integrated peace and good selection training program on improving interpersonal relationships and academic motivation of female high school students
}

\begin{abstract}
Citation: Zamani Kokhalo L, Sepah Mansour M, Abolmaali Kh. The effectiveness of integrated peace and good selection training program on improving interpersonal relationships and academic motivation of female high school students. J of Psychological Science. 2021; 20(105): $1683-1698$
\end{abstract}

Leila Zamani Kokhalo ${ }^{1}$, Mojgan Sepah Mansour ${ }^{2}$, Khadijeh Abolmaali ${ }^{3}$

1. Ph.D Student, Department of Educational Psychology, Central Tehran Branch, Islamic Azad University, Tehran, Iran. 2. Associate Professor, Department of Psychology, Central Tehran Branch, Islamic Azad University, Tehran, Iran.

3. Associate Professor, Department of Psychology, Roudehen Branch, Islamic Azad University, Roudehen, Iran.

URL: https://psychologicalscience.ir/article-1-1107-fa.html
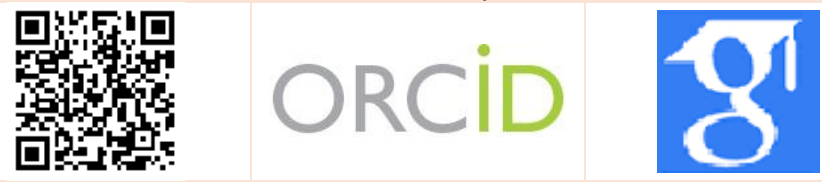

\section{A R T I C L E I N F O A B S T R A C T}

\section{Keywords:}

Integrated peace and good education $\neg$ Choice, Interpersonal relationships, academic motivation
Background: Learning to live together with moral values is one of the major topics in education today. Much research has been done on peace education, but the combination of peace education and good education on academic empowerment, including interpersonal relationships and students' academic motivation, has been neglected.

Aims: The aim of this study was to investigate the effectiveness of peace and integration training on improving interpersonal relationships and academic motivation of female high school students in Tehran.

Methods: The research was conducted by quasi-experimental method with pre-test-post-test design with experimental and evidence group and one-month follow-up. Its statistical population was female high school students in District 19, Tehran (5901 people) in the academic year of 2019-2020. Sample: 40 students were purposefully selected, and randomly divided into 2 groups of 20 people. The research instrument was Diperna and Elliott (1999) Competency Assessment Scale. For the experimental group, an integrated training program for integrated peace and well-being training, including 8 90-minute sessions over 8 consecutive weeks, was implemented. Finally, both post-test and one month later, follow-up test was taken. The collected data were inferentially analyzed by repeated measures analysis of variance and Bonferroni post hoc test with Spss-22 software.

Results: The combined education of peace and good choice had a positive effect on interpersonal relationships and students' academic motivation $(\mathrm{P}<0.01)$. This effect was also significant in the follow-up phase.

Conclusion: Integrated peace and good education can be used as an effective way to improve interpersonal relationships and students' academic motivation.

* Corresponding Author: Mojgan Sepah Mansour, Associate Professor, Department of Psychology, Central Tehran Branch, Islamic Azad University, Tehran, Iran.

E-mail: drsepahmansour@yahoo.com

Tel: (+98) 9121034160

2476-5740/ ( 2021 The Authors. This is an open access article under the CC BY-NC-ND license

(https://creativecommons.org/licenses/by-nc/4.0/). 


\section{Extended Abstract}

\section{Introduction}

Turning schools today into a healthy, dynamic and exciting place to learn the passion of being alive, loving, being together, forgiving, being kind; It is one of the biggest challenges for coaches. What is clear is that the definition of school in the developed world has changed. School is no longer a place to teach science, math, reading and writing to students. Rather, it is a place that can provide the ground for increasing mental health among adolescents and young people, in addition to promoting the academic progress and success of

students. In the future, these students will be messengers of peace and friendship for the world (Hedayati, 1399).

Since adolescence and high school are the most important periods in the life of students; Establishing healthy relationships with classmates or teachers and gaining the individual skills necessary to recognize a healthy and effective life is one of the most important needs of students in this course. Effective communication means the ability to express correct verbal and non-verbal characteristics that are necessary to establish personal communication (Hejazi, Babakhani and Ahmadi, 1397). Training in communication and social skills reduces interpersonal problems (Habibi Kalibar, Farid, Misrabadi and Bahadori Khosroshahi, 1398) and is effective in improving intimacy (Patriots and Wonder, 1399). Students with better interpersonal relationships have a better perception of school and have a positive view of themselves (Holder and Klassin, 2010).

Seagdam (2013) also showed in a study that students' communication skills play an important role in improving education and learning (according to Bahadori Khosroshahi and Habibi Kalibar, 2017).

The motivation for progress reflects the desire to strive for success and its positive effects, avoidance of failure and the negative effects associated with it (Hossein Mardi and Hosseinmardi, 2015). Research has shown that students with high academic motivation experience a higher level of academic achievement (Tripainer, Frent and Austin, 2013, according to Bahadori Khosroshahi and HabibiKalibar, 2017; Yu, Dong and Lim, 2016; Freundland and Worrell, 2016). According to Rowell and Hong (2013), academic motivation is the most important foundation for students' progress and is the main factor in the process of educating students that has not been considered in schools and in the educational system, the value of education is high. It has not been given (Rahmani and Saki, 1396).

Considering that motivational and interpersonal problems can lead to unhealthy relationships and poor academic performance; Familiarity with the factors affecting these variables is undoubtedly effective in determining the future perspective of students. Therefore, it is necessary to use solutions to reduce these problems.

By teaching peace and strengthening interpersonal relationships, by creating awareness and improving skills, and by teaching good choice by flourishing one's intellect and raising one's level of knowledge and enlightenment; It is possible to help form a society in which people live in peace and without violence and aggression. The main goal of peace education is to establish peace between human beings, interpersonal relationships, groups, communities and cultures (Lortizen, 2016).

Therefore, the present study intends to investigate the effect of peace education meaning learning to live together based on moral principles such as forgiveness, patience, trust, spirituality, etc. on improving interpersonal relationships and students' academic motivation. Take the test and find the answer to the question: Does the combined education of peace and good choice have an effect on improving interpersonal relationships and students' academic motivation?

\section{Method}

This research has been done by quasi-experimental method with pre-test-post-test design considering the experimental and control groups with one month follow-up. Its statistical population was the female students of the first year of high school in the 19th district of Tehran (5901 people) who were studying in the schools of this district in the academic year of 2019-2020.The sample size of 40 students of different 


\section{Monthly Journal of Psychological Science}

educational levels of the first year of high school is interested and exit criteria.

\section{Results}

The age of the subjects was between 12 and 14 years old and they were present in the sample groups from all three educational levels (seventh grade $40 \%$, eighth grade $25 \%$ and ninth grade $35 \%$ ). The average of the majority of subjects was between 19.51 and 20 .

Table 1 shows that the mean scores of interpersonal skills and academic motivation of the control group in the three stages of the test do not differ much; But the mean of the variables in the experimental group in the pre-test stage is different from the post-test and follow-up. In order to test the significance of the observed differences, repeated measurement analysis was used to observe its assumptions. The scale of
Vol. 20, No. 105, Autumn(December) 2021

measurement in this study was distance and the sample group, after matching based on the intervening variables, were randomly divided into experimental and control groups.

Pert values were examined and excluded from analysis. With Box-M test, homogeneity of covariance matrices $(\mathrm{P}=0.072<0.05)$, with analysis of variance test, no significant difference between the experiments of the two groups $(=0.583<0.05) \mathrm{P})$ and by drawing scatter diagrams, the assumption of linearity was examined. Shapiro-Wilk test was used to check for normality. Levin test was performed to determine the homogeneity of variances. To check the uniformity of variance of the differences between all compounds related to the groups (sphericity), Machley sphericity test was used.

Table 1. Descriptive indicators of participants' performance in pre-test, post-test and follow-up of research variables

\begin{tabular}{|c|c|c|c|c|}
\hline \multirow{2}{*}{ Variable } & \multirow{2}{*}{ Group } & Pre-test & Post-test & follow-up \\
\hline & & Standard deviation \pm average & Standard deviation \pm average & Standard deviation \pm average \\
\hline \multirow{2}{*}{ Interpersonal skills } & The experiment & $23 / 0 \pm 2 / 10$ & $27 / 7 \pm 1 / 70$ & $28 / 0 \pm 2 / 22$ \\
\hline & Witness & $23 / 0 \pm 2 / 13$ & $23 / 1 \pm 2 / 07$ & $23 / 1 \pm 2 / 07$ \\
\hline \multirow{2}{*}{ Academic motivation } & the experiment & $24 / 3 \pm 2 / 13$ & $30 / 6 \pm 2 / 26$ & $30 / 7 \pm 2 / 23$ \\
\hline & Witness & $24 / 0 \pm 2 / 2$ & $24 / 2 \pm 2 / 14$ & $24 / 2 \pm 2 / 14$ \\
\hline
\end{tabular}

Table 2. Summary of the results of the test of natural distribution of scores and the test of homogeneity of variances

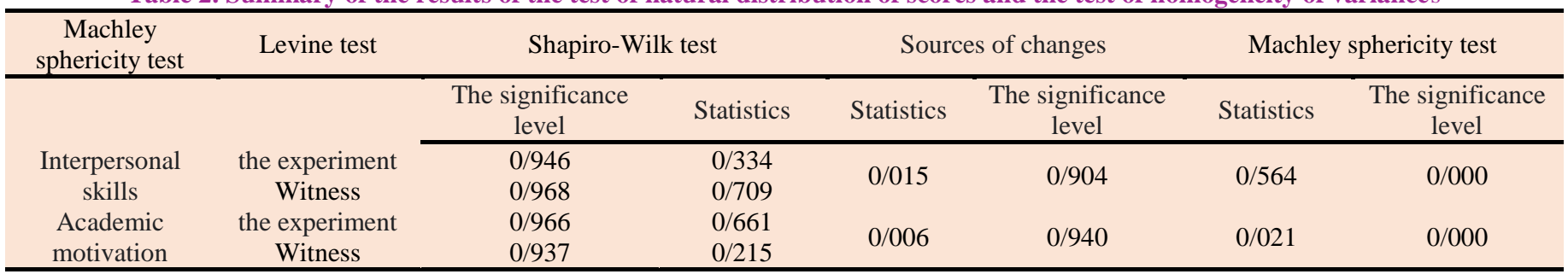

The data in Table2, Shapiro-Wilk test, indicate that the distribution of interpersonal skills and academic motivation scores is normal $(\mathrm{P}>0.05)$. Levin test also showed that there was no significant difference in the variance of intrapersonal skills scores and academic motivation in the three stages $(\mathrm{P}<0.01)$. According to Machley sphericity test, the sphericity assumption is not valid for variables $(\mathrm{P}<0.05)$. Therefore, the modified Epsilon Greenhouse-Geiser test of variance was used.

\section{Conclusion}

According to Lorizen (2016), the main goal of peace education is to establish peace between human beings, interpersonal relationships, groups, countries, communities and cultures. By training and reinforcing knowledge, skills, attitudes, and values that change behavior, these trainings enable students to avoid conflict, both overt and structural. To resolve conflicts peacefully, to educate, to educate, to teach moral values, to resolve conflicts and to prevent violence; emotional compatibility and mental health; Positive and supportive communication between students has been effective and has promoted interpersonal skills and academic motivation and thus has been effective in the development of students' academic competence. 
In order to communicate it effectively, it is important to pay attention to its principles and contexts. It can be argued that these teachings are often propositions that affect an individual's performance at both the cognitive and behavioral levels.

In the modern world, progress and changes in the economic, political and economic fields have not been able to reduce the unwanted behavior of individuals in society. Increasing violence in society and behaviors such as immorality, intolerance, violent tendencies, trying to untie knots by using violent methods that students show inside and outside the school, indicates that individuals can not adequately adopt the expected positive behaviors, and this requires the creation and development of a culture of peace based on equality, justice, democracy, human rights, tolerance and solidarity in society (Marzooqi, Mohammadi, Shamshiri and Dadgar, 1396).

Good mood has a tremendous effect on human relations and creates love and closeness of hearts to each other, which provides a basis for deep and lasting relationships. The many effects that good character leaves on the lives of human beings and the great emphasis on the Qur'an and the Ahl al-Bayt (AS) show its great importance. Among the works of good manners, we can mention the aspect of bonding and consolidating it in relationships. Good mood causes the society to reach a kind of internal convergence and solidarity and strengthens its foundations from within.

Studies on peace education and moral values, education on issues such as coordination, conflict resolution, nonviolence or non-conflict, human rights, social justice, global environment and multicultural understanding have been introduced as components of behavior.

Creating positive attitudes and beliefs about selfrespect and others and striving for justice and nondiscrimination through education, as well as the principles, concepts and peaceful relationships can be promising to apply these teachings in the future lives of individuals.
Therefore, what should be considered in the meantime is to make the necessary changes in the systems of production and reproduction of violence, insecurity and discrimination, to resolve crises, hostilities and conflicts. These changes require peace education at all levels of society and increasing attention to it in formal, informal and tacit education systems. Therefore, developing a curriculum that is sufficient for scientific and practical peace education in schools is an issue that should be given serious attention (Marzooqi et al., 2017).

Fundamental global changes are on the way and we will surely see various global issues and problems in the coming years. For this reason, our students should be aware of these issues and problems, and to achieve this awareness, global education will be required. The goal of global education is to expand one's understanding of one's world. People with global awareness understand the multicultural and transnational nature of human conditions and the concept of peace. Courses should include information and knowledge about other parts of the world so that students can better understand themselves and their relationships with other people, other cultures and global issues, and achieving this requires a global perspective.

\section{Ethical Considerations}

Compliance with ethical guidelines: This article is taken from the doctoral dissertation of the first author in the field of educational psychology in the Islamic Azad University, Central Tehran Branch, with the activity code 10120702982005 and the date of approval of the proposal is 04/19/1397. Also, permits related to research in the statistical community have been issued by the Education Organization in District 19.

Funding: This study was conducted as a $\mathrm{PhD}$ thesis with no financial support.

Authors' contribution: This study was conducted as a $\mathrm{PhD}$ thesis with no financial support.

Authors' contribution: The first author is the main researcher of this research. The second author is the supervisor and the third author is the consultant.

Conflict of interest: The authors declare no conflict of interest for this study.

Acknowledgments: I would like to appreciate the supervisor, the advisor, the participants, and district education officials19 in Tehran, Iran. 


\section{اثربخشى آموزش تلفيقى صلح و حسن تزينى بر بهبود روابط بينفردى و انتيزه تحصيلى دانش آموزان دختر دوره اول متوسطه}

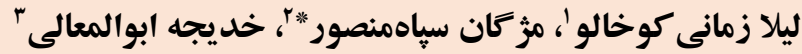

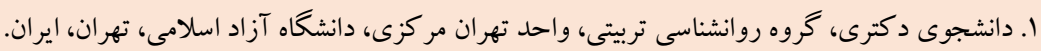

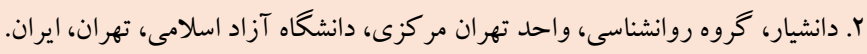

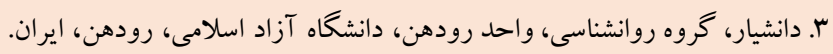

مشخصات مقاله

زمينه: يادگيرى براى باهم زيستن همر اه با ارزشهاى اخلاقى، از موضوعات عمده در تعليم وتربيت امروزه است. يُروهشهاى بسيارى

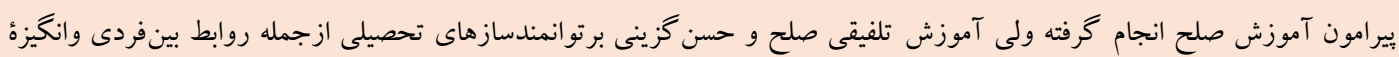
تحصيلى دانش آموزان مغفول مانده است. هدف: هدف تُوهش حاضر بررسى اثربخشى آموزش تلفيقى صلح و حسن گزينى بر بهبود روابط بينفردى وانظيزة تحصيلى دانش آموزان دختر دوره اول متوسطه تهران بود.

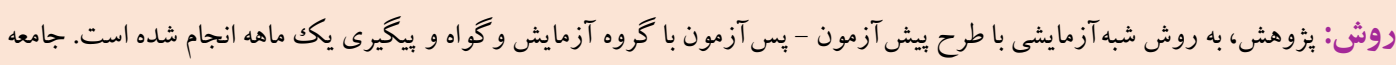

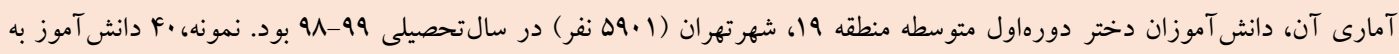

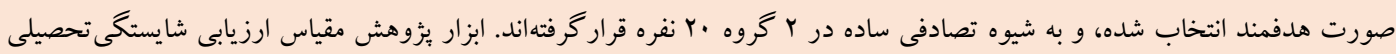

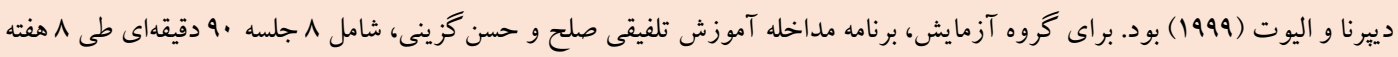

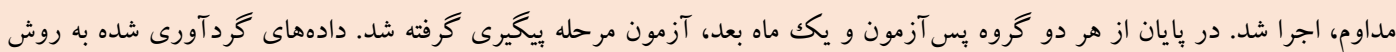

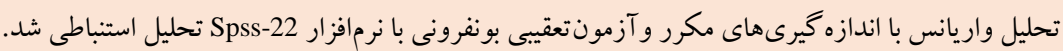

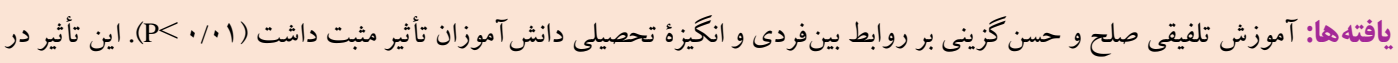

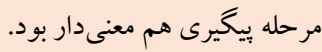

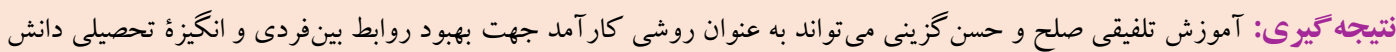
آموزان مورد استفاده قرار گيرد.

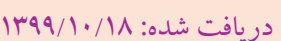
يذيرفته شده: • ب/||/

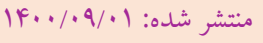

* نويسنده مسئول: مزّكان سياهمصور، دانشيار، گروه روانشناسى، واحد تهران مر كزى، دانشكاه آزاد اسلامى، تهران، ايران. رايانامه: drsepahmansour@yahoo.com

تلفن: 
مهارتهاى ارتباطى و اجتماعى، باعث كاهش مشكلات بين فردى مى گردد

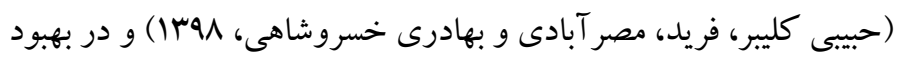

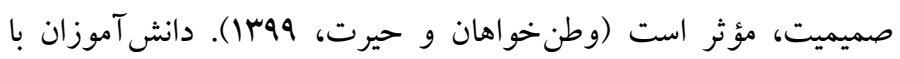

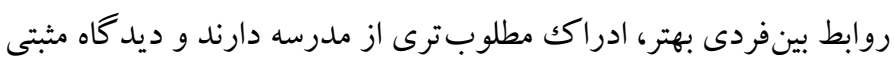

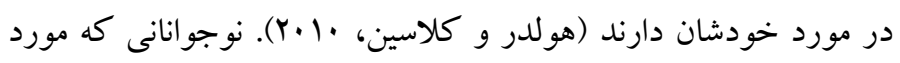

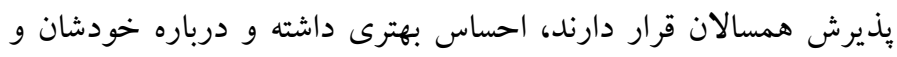

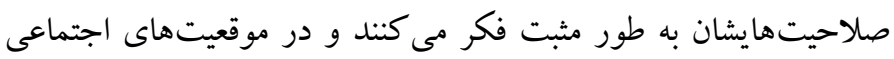

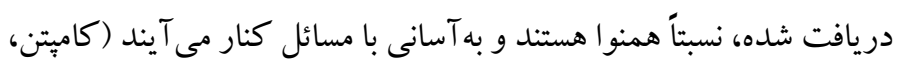

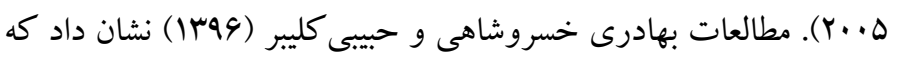

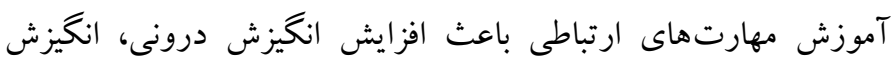

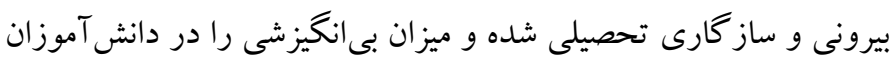

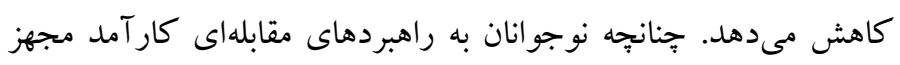

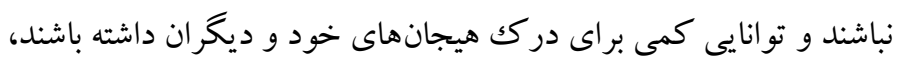
در برخورد با فشارها و بحرانهاى نوجوانى توان كمترى داشته و داراى دوري

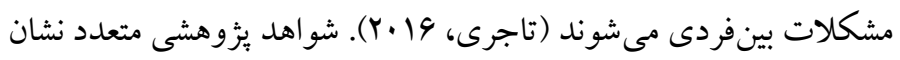

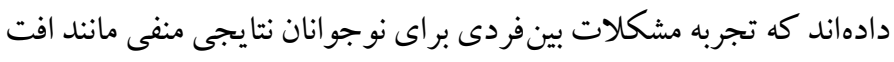
عملكرد تحصيلى، احساس تنهايى، خود كشى، تركك زود هنگام مدرسه،

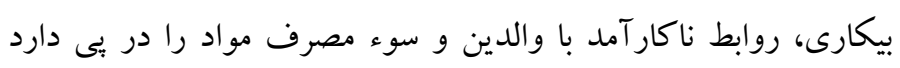

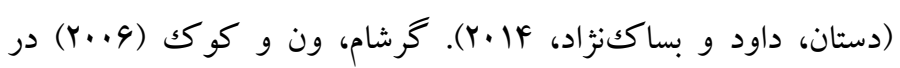

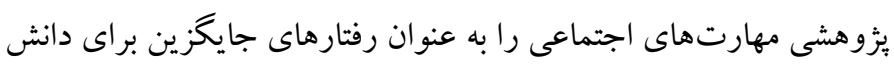

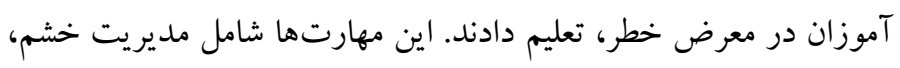
دوست يابى، ابراز وجود و ارتباط بوده است. نتايج مطالعات كرد نوقابى و

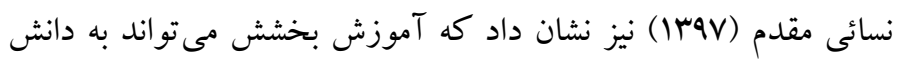

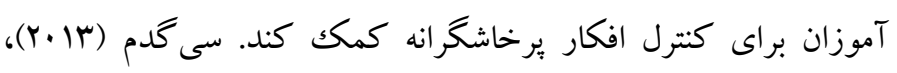

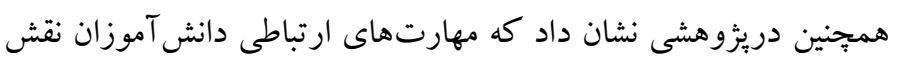

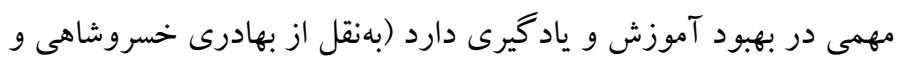

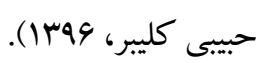
روابط بينفردى و انخيزه تحصيلى دو مورد از خرده مقياسهاى

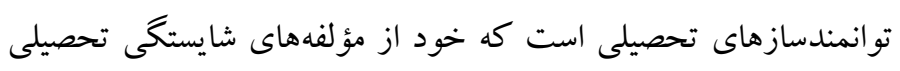

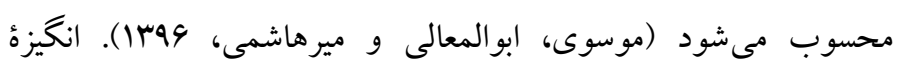

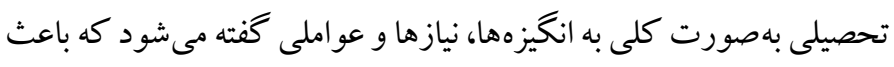
حضور يكك فرد در محيط آموزشى و كسب مدركك تحصيلى مى گردد
مقدمه

امروزه تبديل مدارس به مكانى سالم، يويا و مهيج كه شور و شوق زنده

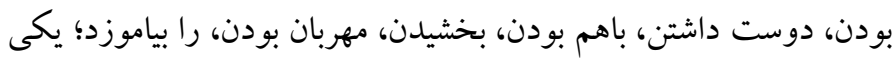

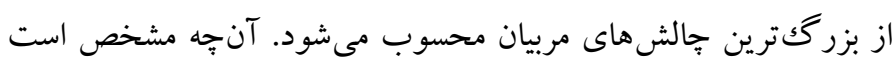
آن است كه تعريف مدرسه در دنياى توسعه يافته تغييرييدا كرده است. مدرسه ديخر مكانى محسوب نمىشودكه علوم، رياضيات، خواندن و

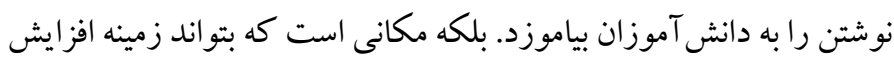

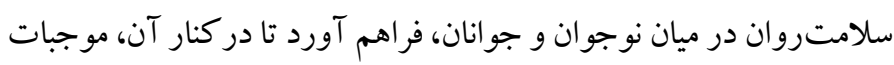
يُشرفت و موفقيت درسى دانش آموزان هم بهوجود آيد. اين دانش آموزان اندان

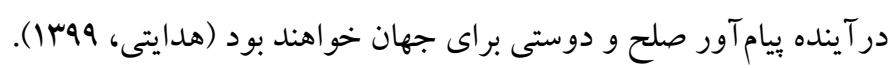

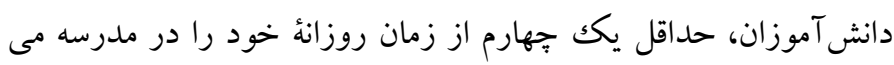

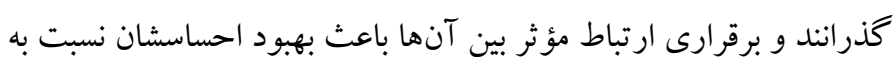

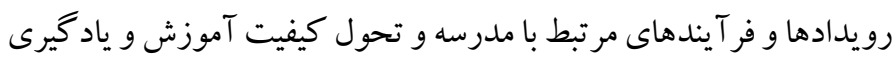

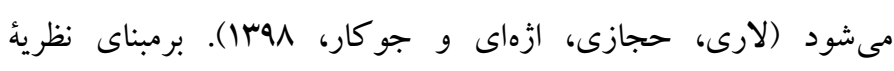

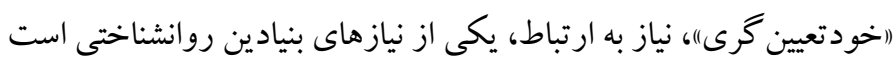

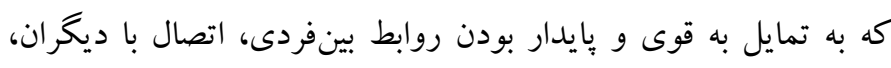

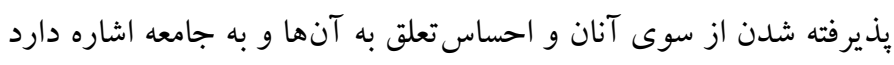

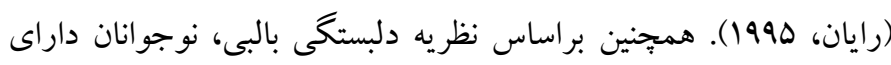

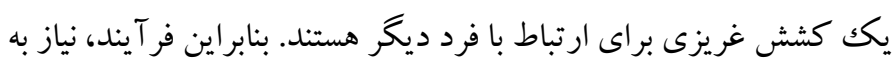

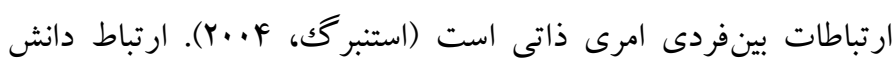

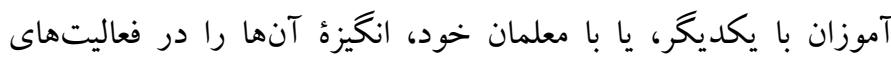

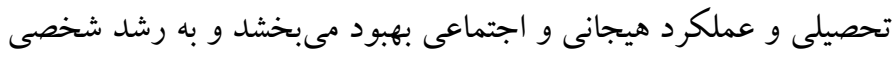

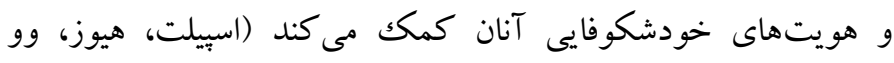

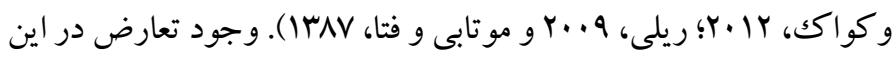

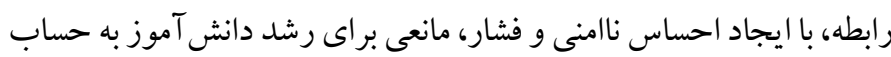

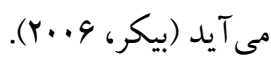
از آنجا كه نوجو انى و دوره متوسطه از مهم ترين دورههاى زندآنى دانش

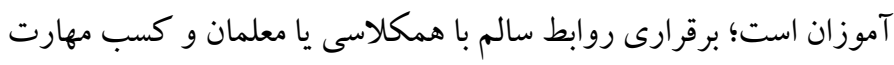

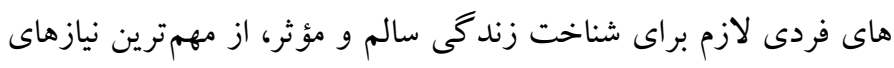
دانش آموزان در اين دوره است. منظور ازارتباط مؤثر، توانايى ابراز

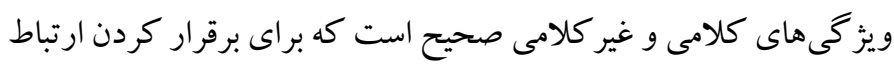

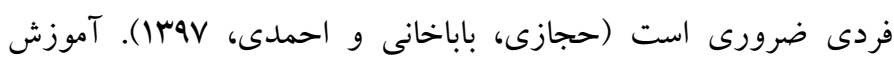


هم" و (شكوفاسازى عقل براى بهدست آوردن بصيرت و توانايى شناسايى حُسن و قبح افعال) است. با آموزش صلح و تقويت روابط بين فردى، از طريق ايجاد آكاهى و ارتقاء

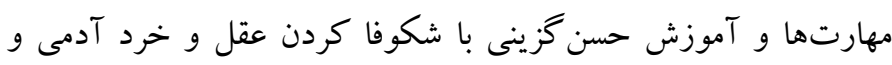

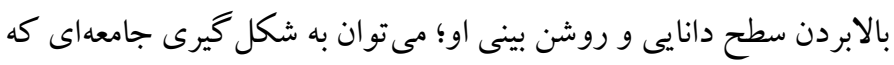

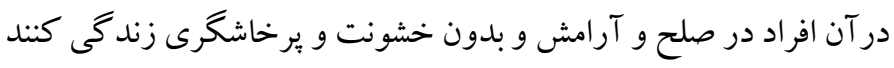
كمك كرد. هدف اصلى آموزش صلح، برقر ارى صلح ميان انسانها، روابط ونط

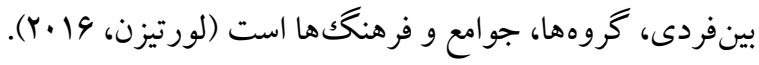

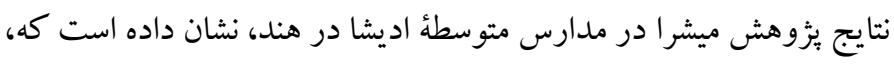

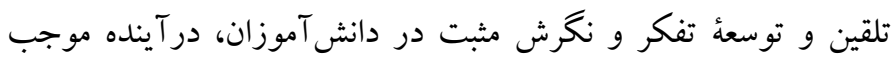
دستيابى به اهداف نهايى بهتر و جامعهاى صلح آميز خواهد شد. افزون بر

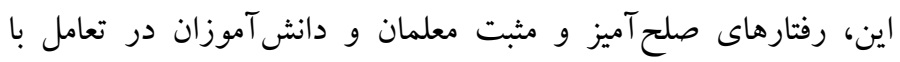

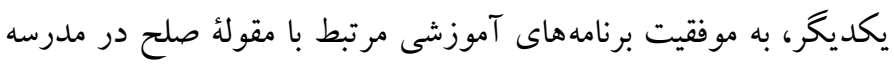

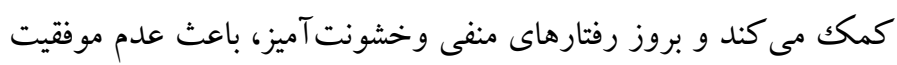

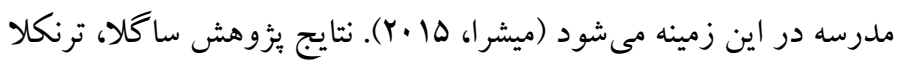

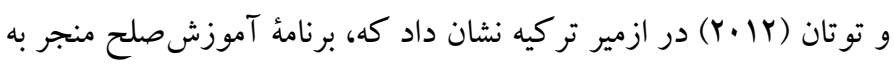
افزايش سطح همدلى در دانش آموزان شده است. اوكو، ايگكبينو كاو اوديو

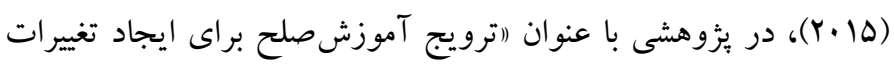

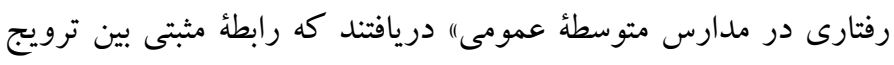

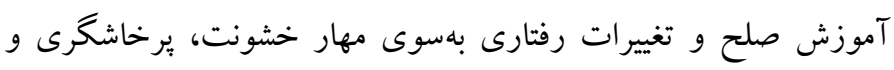

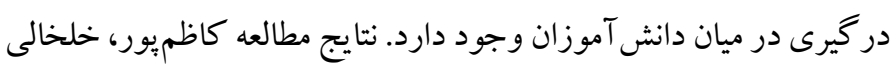

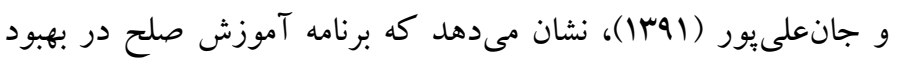
تربيت و افزايش دانش، توانش و نخرش شهروند جهانى فراكيران تأثير دارد. همجينين در مطالعات لوت جونز، لاتلين، هيخينز و مكك ميلان

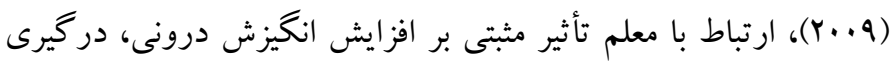

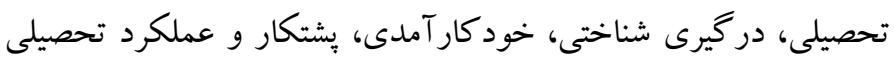

صاحبنظران تربيتى، مسالة تربيت اخلاقى را از نيازهاى ضرورى هر جامعه

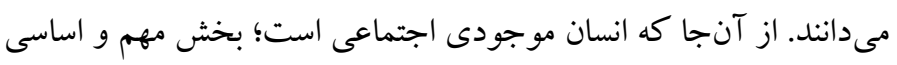

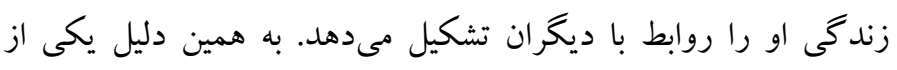

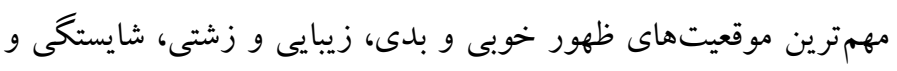

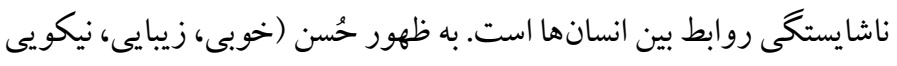

(كلاركك و شروت، • •(Y). منظور از انخيزش بيشرفت، ميل يا اشتياق براى

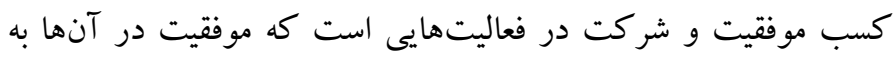

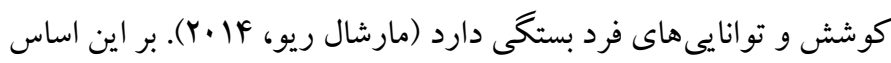

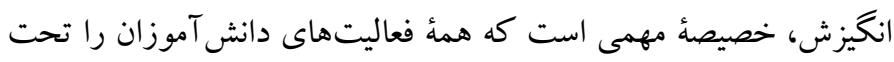

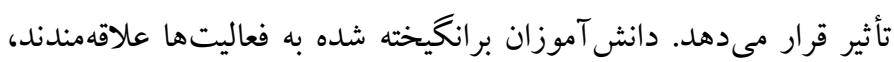
سختكوش هستند، اعتماد به نفس دارند، در انجام تكاليف استمرار نشان

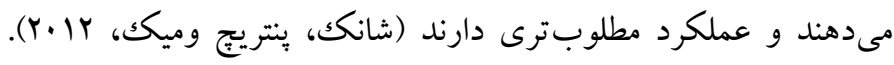

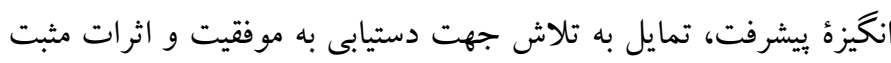

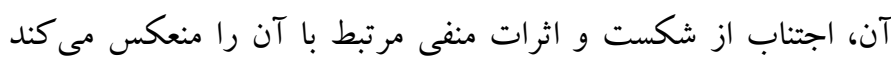

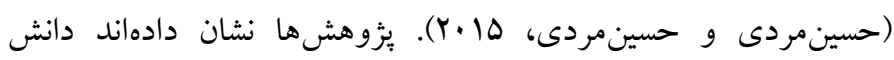
آموزانى كه انگيزش تحصيلى بالايى دارند، سطح بالاترى از بيشرفت

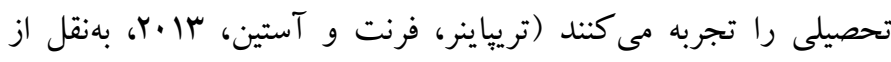

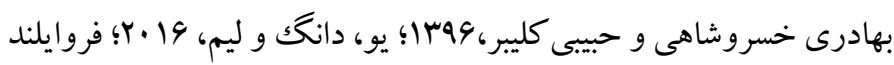

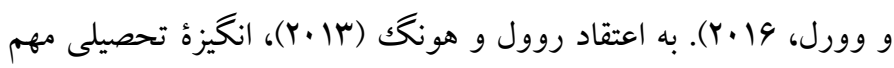

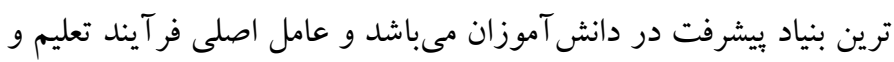

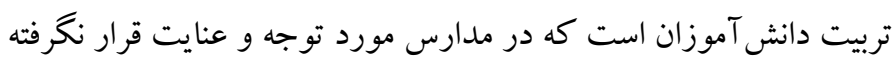

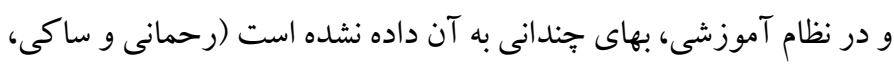

(1)99

با اين فرض كه انگيزش بر تمام ابعاد تحصيلى تأثير گذار بوده و برموفقيت

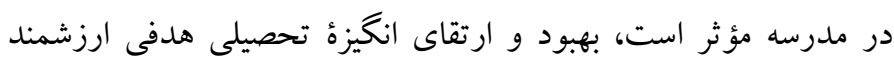

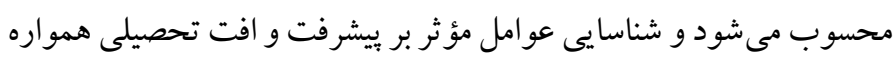

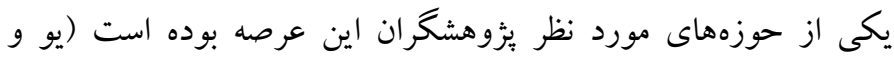

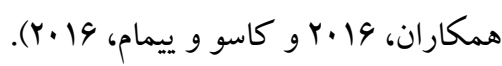

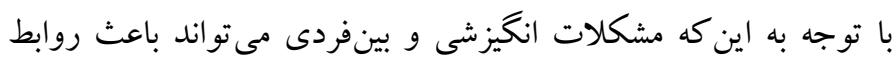

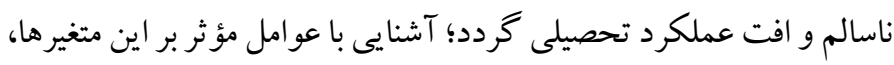
بى شك در تعيين دورنماى آينده دانش آموزان تأثير گذار است. بنابراين

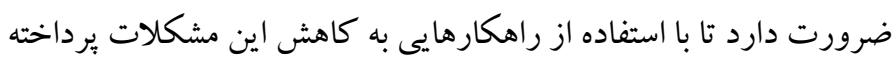

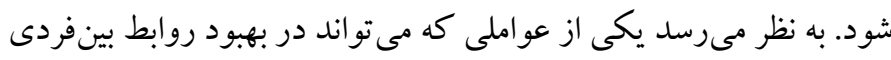

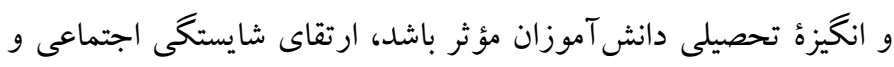

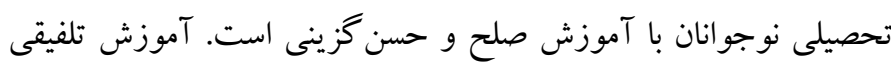

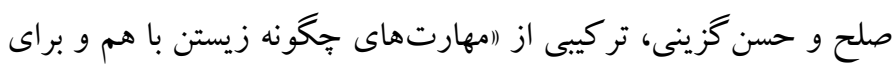


بِاسخ اين سؤال است كه: آيا آموزش تلفيقى صلح و حسن گزينى، بر بهبود

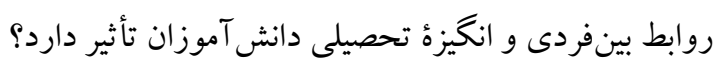

روش

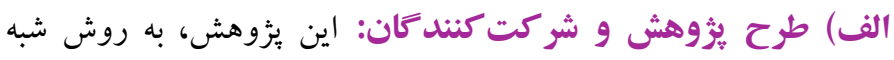

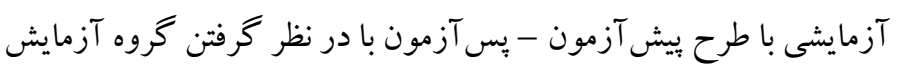

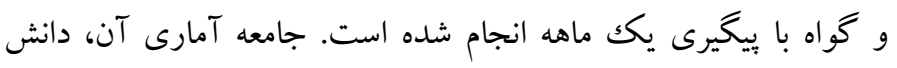

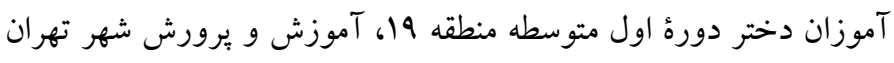

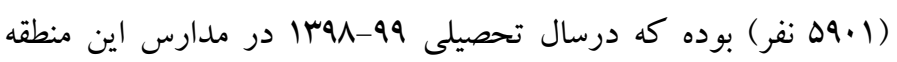

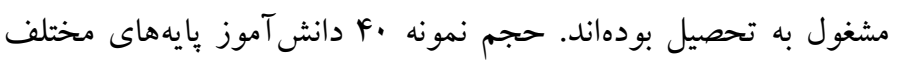

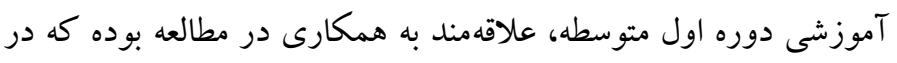

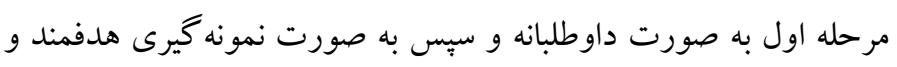

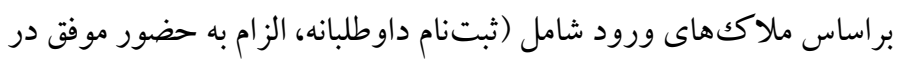

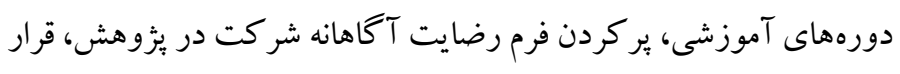

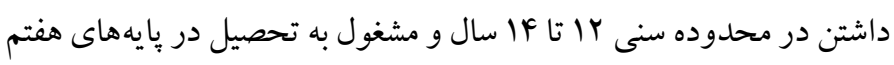
تا نهم متوسطه، عدم ابتلاء به بيمارىهاى جسمى مزمن در زمان انجام

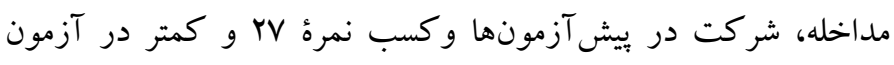
ارزيابى شايستگى تحصيلى (بخش روابط بينفردى) و نمره هو و و كمتر

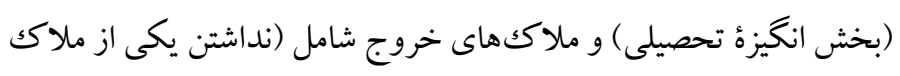

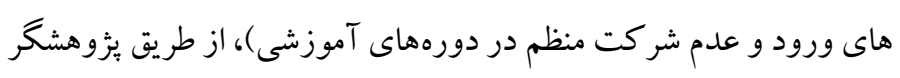
معرفى شده و بس از همتاسازى به لحاظ سن، بايه تحصيلى و نمره بيش

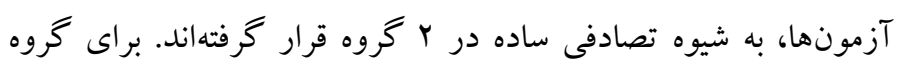

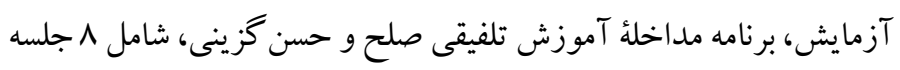

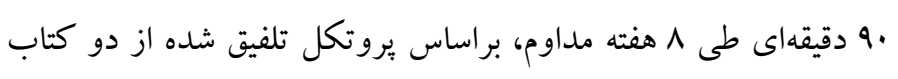

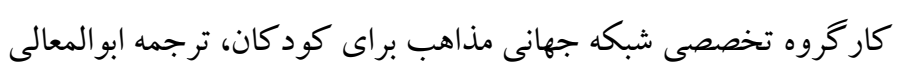

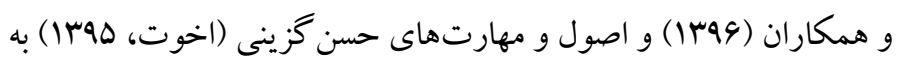

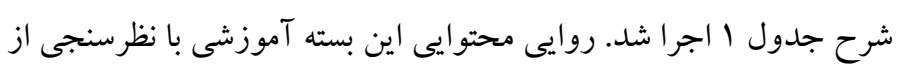
متخصصين و محاسبه CVR و CVI مورد بررسى و تأييد قرارگرفت.

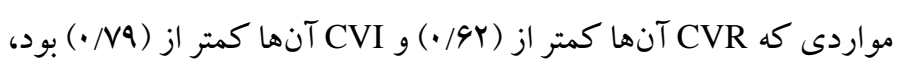

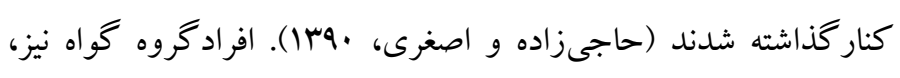

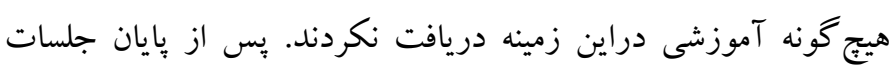

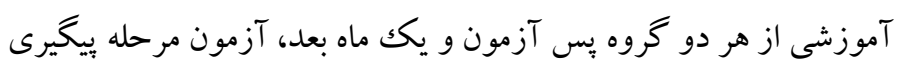

و شايستخى) در ارتباط با ديخران، (احسان) كفته شده است كه مىتواند با

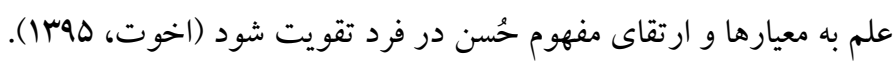

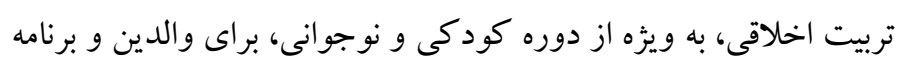

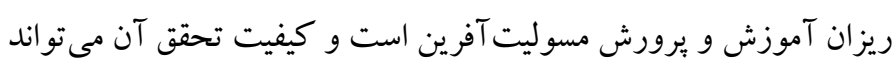

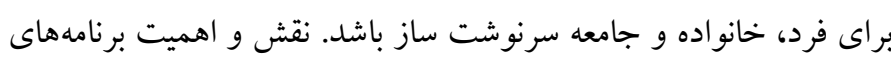
درسى در رشد تربيت اخلاقى بسيار حساس است و فقدان برنامه ريزى

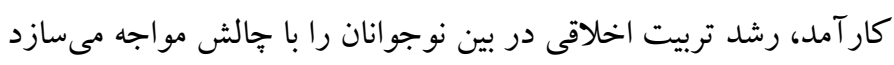

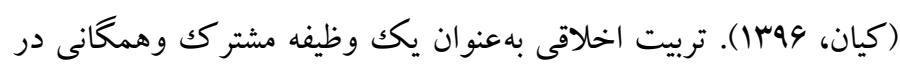
جامعه از سوى نهادهاى مختلف مورد بيخيرى قرار مى گيرد (آرتور،

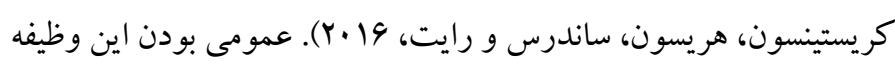

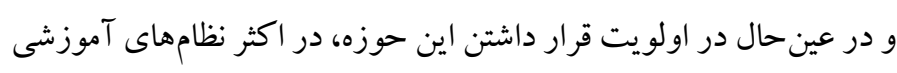

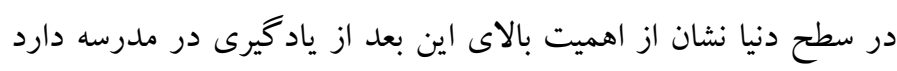

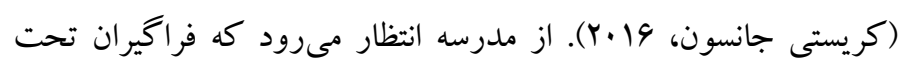

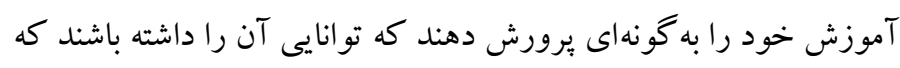

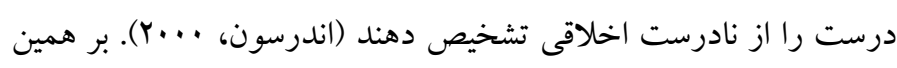
اساس تربيت اخلاقى هميشه يكى از اهداف اصلى و بايدار در نظامهاى داى دهن

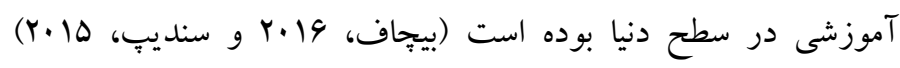

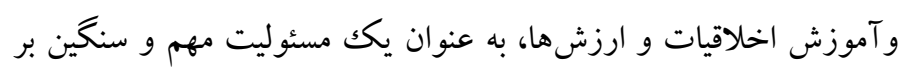
دوش نظامهاى آموزشى و تربيتى جهان احساس مى شود (كريستى

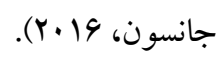
در مجموع با در نظر گرفتن مشكلات انخيزشى و بين فردى در نوجوانان و با افزايش اين مشكلات و نقش اساسى اخلاق و ياد گيرى براى باهم زيستن

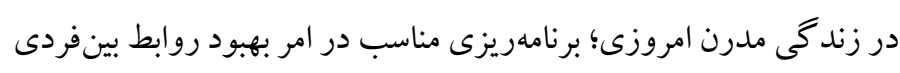

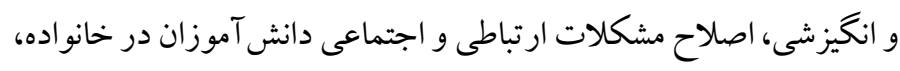

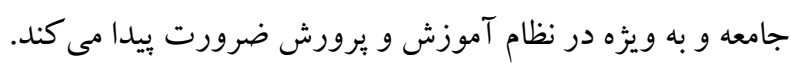

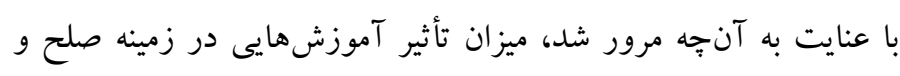

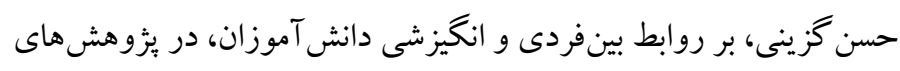

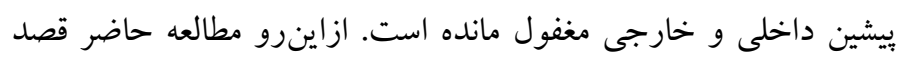

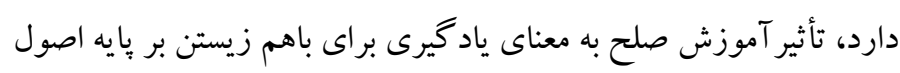

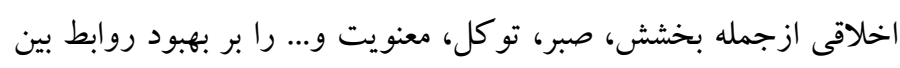

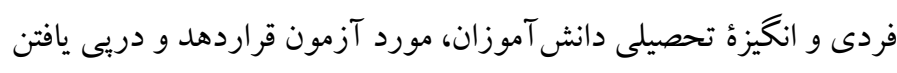


بايايى محاسبه شده NF/ · بود كه اعتبار برسشنامه را تأييد مى كند. انخيزه

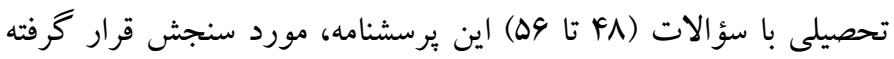

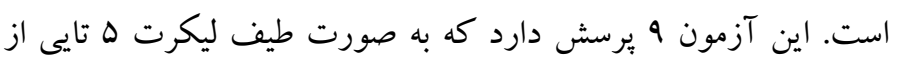

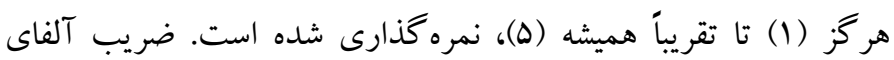

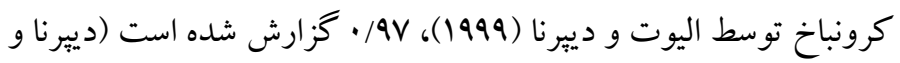

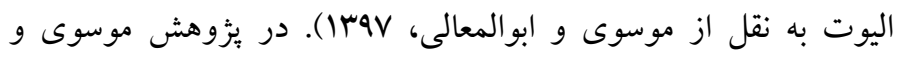

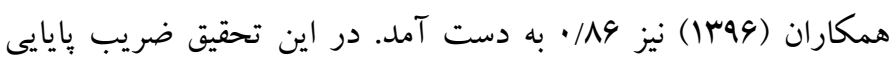

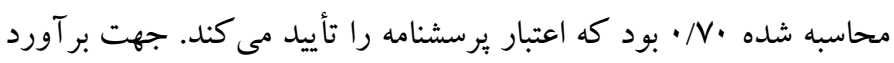
روايى برسشنامها از ديد گاه متخصصان بهره گرفنه شد. بود.

يافته ها

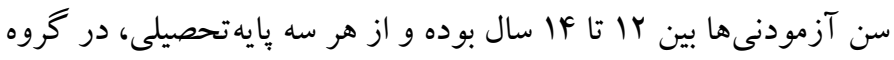

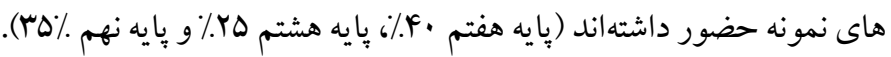

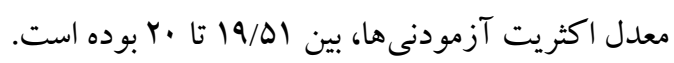

كرفته شد. به منظور رعايت اصول اخلاقى يثزوهش، در مورد محرمانه بودن اطلاعات، به نمونههاى يُزوهش اطمينان داده شد. در نهايت با استفاده از

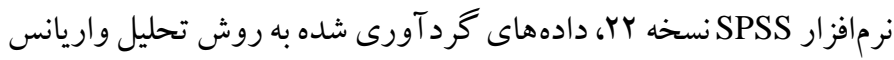

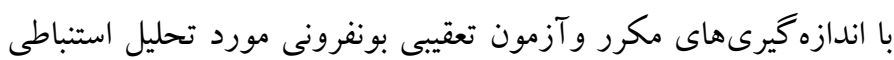
قرار كرفته است.

ب) (بزاز دادهها، طى سه مرحله ازطريق، برسشنامه ارزيابى شايستخى تحصيلى ديبرنا

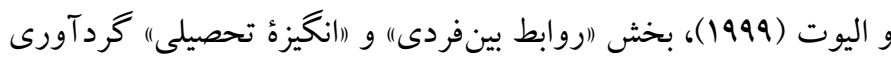
شده است. به منظور ارزيابى مهارتهاى بين فردى از سؤ الات ( اس تا هو)

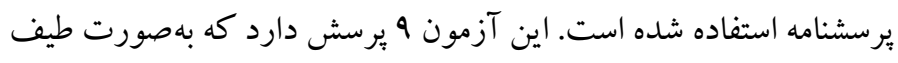

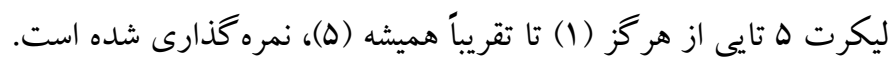

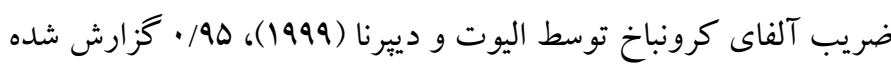

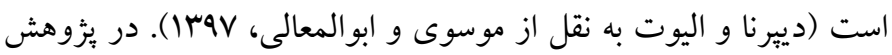

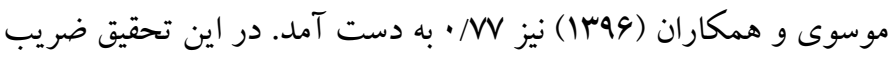

جدول ا. جلسات آموزش ثلفيقى صلح و حسن ززينى، اهداف و محتواى هر جلسه

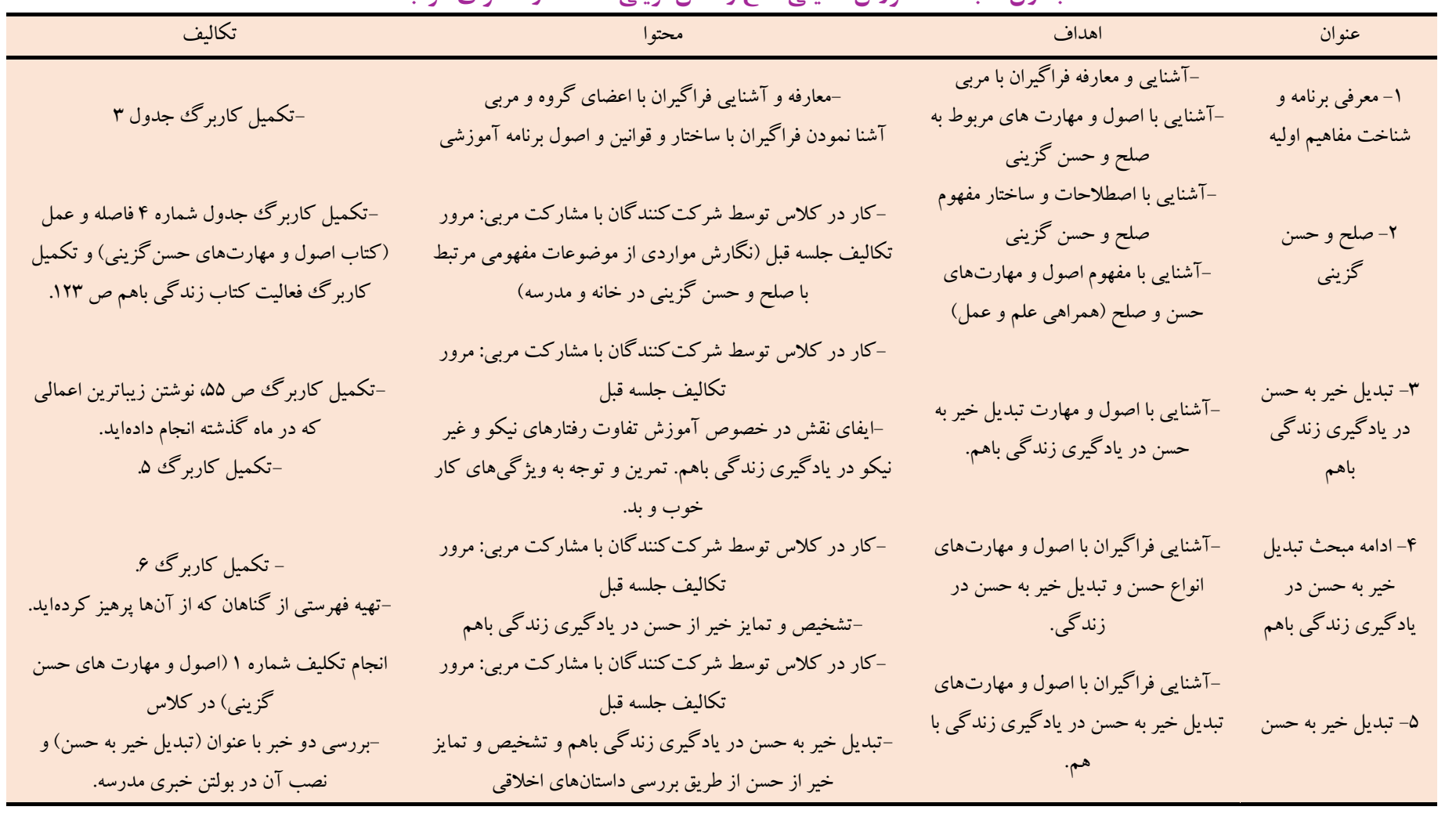




\begin{tabular}{|c|c|c|c|}
\hline تكاليف & محتوا & اهداف & عنوان \\
\hline 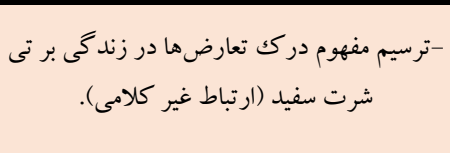 & -دركى تعارضها، تضادها و بىعدالتىهاى اطراف من و خلق & 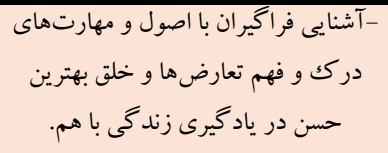 & 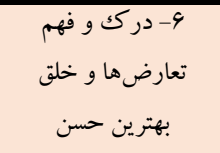 \\
\hline 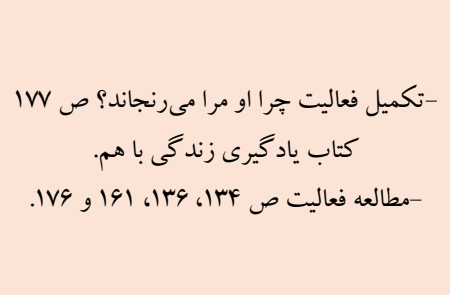 & 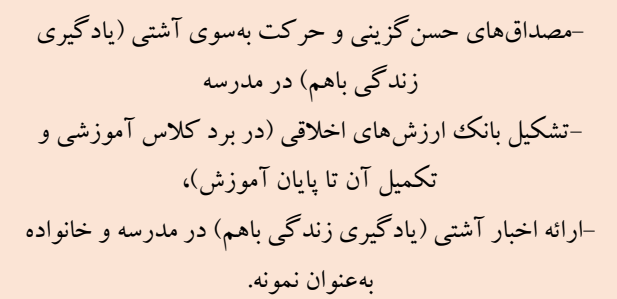 & 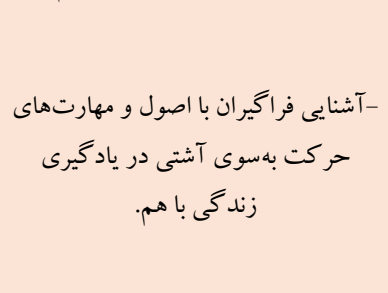 & 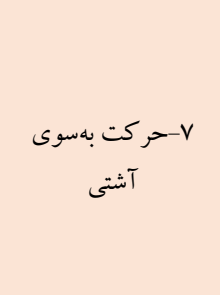 \\
\hline 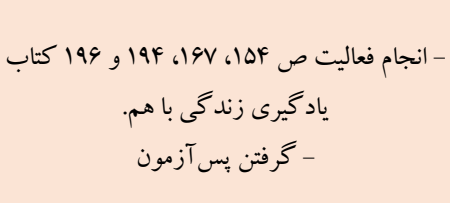 & 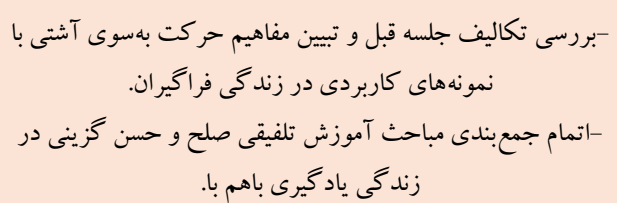 & 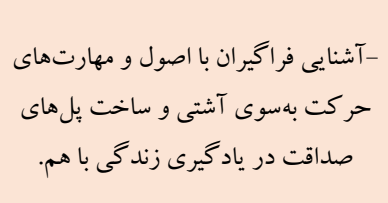 & ب- بـ ادامه بحث حرى آشتى و ساخت \\
\hline
\end{tabular}

همتاسازى براساس متغيرهاى مداخله گر به طور تصادفى ساده در دو گروه يافته ها

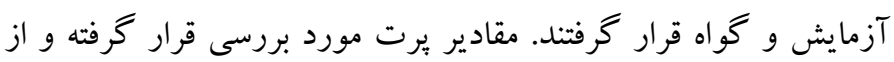

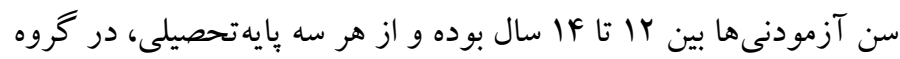

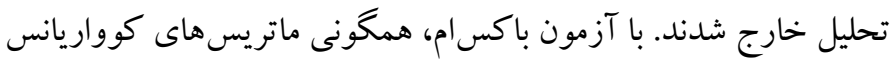

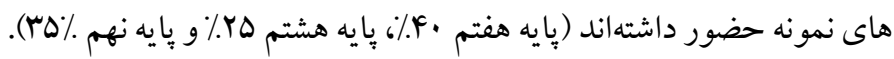

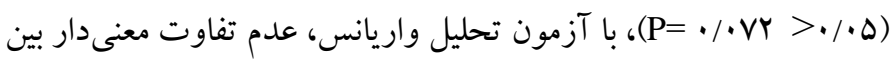

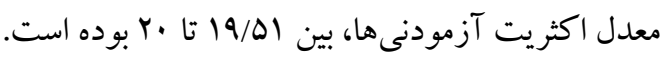

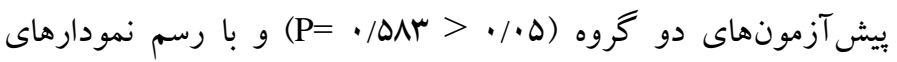
در جدول ب مشاهده مىشود، ميانگين نمرات مهارت هاى بين فردى و انخيزهُ

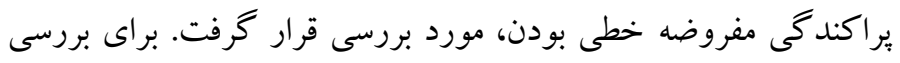

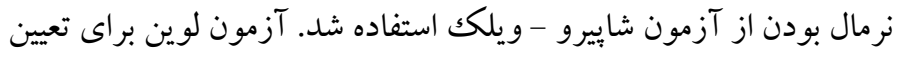
تحصيلى گروه گواه درسه مرحله آزمون تفاوت زيادى ندارد دارد؛ اما

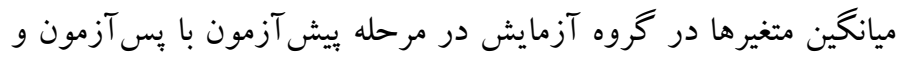

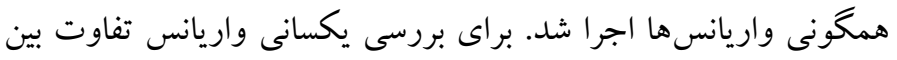

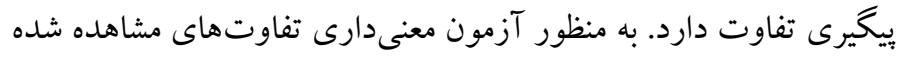

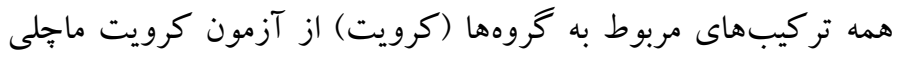

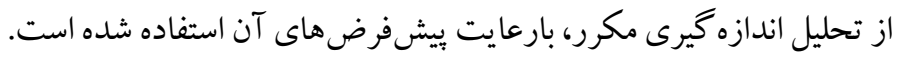

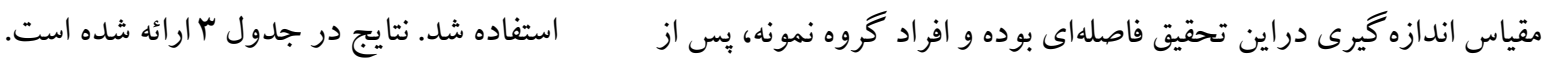

\begin{tabular}{|c|c|c|c|c|}
\hline ييخيرى & يس آزمون & ي يش آزمون & \multirow{2}{*}{ كروه } & \multirow{2}{*}{ متغير } \\
\hline انحرافمعيار 土ميانخين & انحر افمعيار \ميانخين & انحر افمعيار 土 ميانخين & & \\
\hline$Y N / Y \pm \cdot / Y Y$ & $r V / I \pm F / V$. & $r r / r \pm \cdot / l$. & آزمايش & \multirow[b]{2}{*}{ مهارت هاى بين فردى } \\
\hline$r / r \pm 1 / \cdot V$ & $r r / r \pm 1 / \cdot V$ & & كواه & \\
\hline$r \cdot / r \pm V / r r$ & $r \cdot / r \pm 9 / r q$ & $r F / r \pm r / I r$ & آزمايش & \multirow{2}{*}{ انخيزه تحصيلى } \\
\hline$Y F / Y \pm Y / I F$ & $Y F / Y \pm Y / I F$ & $Y F / Y \pm \cdot / r$ & كواه & \\
\hline
\end{tabular}

\begin{tabular}{|c|c|c|c|c|c|c|c|}
\hline \multicolumn{2}{|c|}{ آزمون كرويت ماجلى } & \multicolumn{2}{|c|}{ آزمون لوين } & \multicolumn{2}{|c|}{ آزمون شاييرو - ويلكك } & \multirow{2}{*}{ منابع تغييرات } & \multirow{2}{*}{ 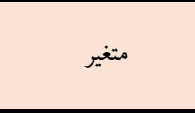 } \\
\hline سطح معنى دارى & T آماره & سطح معنىدارى & Tاره & سطح معنىدارى & آماره & & \\
\hline$\cdot \cdots$ & $\cdot / \Delta G A$ & $\cdot / 9 \cdot F$ &.$/ 10$ & $\begin{array}{l}\cdot / r H F \\
\cdot / V \cdot q\end{array}$ & $\begin{array}{l}. / 941 \\
. / 991\end{array}$ & كواه & مهارت هاى بينفردى \\
\hline$\cdot \cdots$ & $/ \cdot r \mid$ &.$/ 94$. & .1 .04 & $\begin{array}{l}\cdot / 991 \\
\cdot / Y 10\end{array}$ & $\begin{array}{l}. / 999 \\
. / 94 V\end{array}$ & 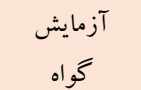 & انخيزه تحصيلى \\
\hline
\end{tabular}


آزمون لامبدا ويلكز در جدول ₹ نشان مىدهد، بين ميزان مهارتهاى بين فردى و انگيزهُ تحصيلى دانش آموزان در سه مرحله اجراى آزمون، تفاوت معنىدارى وجود دارد (1 (P<). به اين معنى كه نمره متغيرها در طول دوره تحقيق در حال تغيير بوده است. همجنين اثرمتقابل مرحله آزمون و كروه نيز معنادار است (1 (P<). بنابراين استفاده ازآزمون تحليل واريانس با اندازه گيرى مكرر مجاز مىباشد. نتايج تحليل واريانس اندازه كيرى مكرر با عدم برقرارى مفروضه كرويت در جدول هارائه شده است.
دادههاى جدول א، آزمون شاييرو - ويلكك، حاكى از نرمال بودن توزيع نمرات مهارتهاى بينفردى و انكيزه تحصيلى است (ه • • P>). آزمون لوين همجنين نشان داد كه تفاوت معنىدارى در واريانس نمرات مهارت هاى بين فردى و انخيزهُ تحصيلى در سه مرحله مشاهده نشد ( (P> P). بر اساس آزمون كرويت ماجِلى، براى متغيرها، مفروضه كرويت برقرار نيست (ه • • (P>) بنابراين از آزمون تحليل واريانس تعديل يافته إيسيلون كرين هاوس - كايسر استفاده شد.

جدولع. آزمونهاى جندمتغيره مربوط به اثرات درون تروهى متغيرها

\begin{tabular}{|c|c|c|c|c|c|c|c|}
\hline مجذور اتا & سطح معنى دارى & درجه آزادى خطا & درجه آزادى فرضيه & $\mathrm{F}$ & لامبدا ويلكز & منابع تغييرات & متغير \\
\hline$\cdot / v \cdot 4$ & $\cdot / \cdots$ & $r V$ & $r$ & $F F / M T V$ &.$/$ rqf & مرحله آزمون & \multirow{2}{*}{ مهارتهاى بين فردى } \\
\hline.$/ 9 \wedge \mathrm{V}$ & $\cdot / \cdots$ & rv & r & $r \cdot / \Delta G r$ & rוr/. & مرحله ×گروه & \\
\hline ./VG. & $\cdot / \cdots$ & rv & r & $\Delta N / \Delta r \Delta$ & . MF. & مرحله آزمون & \multirow{2}{*}{ انخيزه تحصيلى } \\
\hline / NMG & $\cdot / \cdots$ & rv & r & DI/GYV & . TYG & مرحله ×گروه & \\
\hline
\end{tabular}

جدوله. نتايج آزمون اثرات درون كروهى متغير ها به روش كرين هاوس-كايسر

\begin{tabular}{|c|c|c|c|c|c|c|c|}
\hline مجذور اتا & سطح معنىدارى & $\mathrm{F}$ & ميانگين مجذورات & درجه آزادى & مجموع مجذورات & \multicolumn{2}{|c|}{ منابع تغييرات } \\
\hline $.19 \Delta F$ & $\cdot / \cdots$ & VI/VRD & $1.9 / 49$ & 1/rar & $|Q T / Y| V$ & مرحله & \\
\hline.$/ 944$ & $\cdot / \cdots$ & $9 \Delta / 191$ & $1 \cdots / r_{4}$ & 1/rar & $|r q / A| V$ & مرحله ×گروه & مهارت هاى بين فردى \\
\hline & & & l/Drr & $\Delta T / Q F$ & $1 . / 9 \pi r$ & خطا (مرحله) & \\
\hline$\cdot / \mathrm{V} \Delta \Lambda$ & $\cdot / \cdots$ & WN/AYT & rA./AqT & $1 / \cdot 11$ & YAY/AD & مرحله & \\
\hline$\cdot / M H F$ & $\% \cdots$ & $1 . F / v q$. & YFV/DII & $1 / \cdot 11$ & $r \Delta . / I I V$ & مرحله ×گروه & انخيزه تحصيلى \\
\hline & & & T/MGY & rN/F. & $q \cdot / v$. & خطا (مر حله) & \\
\hline
\end{tabular}

(ييش آزمون، بِ آزمون و ييخيرى) در گروه گواه و آزمايش با هم تفاوت

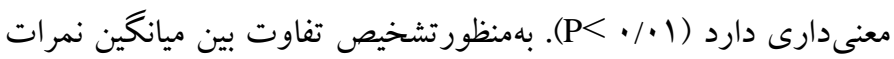

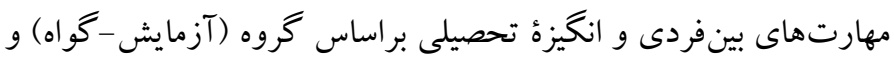
مر حله آزمونها از آزمون تعقيبى بونفرونى، استفاده شده است.
نتايج تحليل واريانس در جدول ه، نشان مىدهد كه تفاوتهاى مشاهده

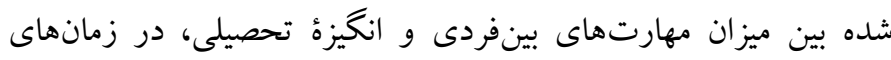

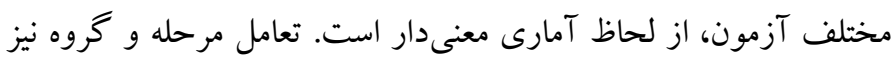

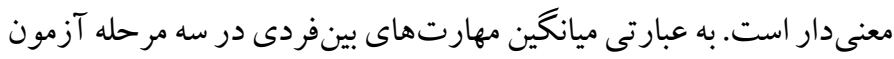

جدولح. آزمون تعقيبى بونفرونى براى بررسى تفاوتها در متغير براساس تروه و مرحله آزمونها

\begin{tabular}{|c|c|c|c|c|c|c|c|}
\hline \multicolumn{2}{|c|}{ فاصله اطمينان تفاوت هـ٪ } & \multirow{2}{*}{ سطح معنى دارى } & \multirow{2}{*}{ انحر اف معيار } & \multirow{2}{*}{ تفاوت ميانگين } & \multirow{2}{*}{ منابع تغييرات } & \multirow{2}{*}{ 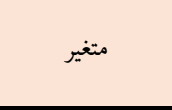 } & \\
\hline حد بالا & حد بايين & & & & & & \\
\hline$-1 / 940$ & $-Y / \Lambda / Q$ & $\% \cdots$ & - & $-Y / Y Y \Delta *$ & يِيش آزمون - يس آزمون & مهارتهاى بين & \multirow{6}{*}{ مرحله آزمون } \\
\hline$-1 / \Lambda \cdot V$ & $-r / T F \mu$ & $\% \cdots$ & $\cdot /$ TAQ & $-Y / \Delta Y \Delta *$ & يِش آزمون - ييگيرى & فردى & \\
\hline .1 .91 & -.1991 & . / IFF &.$/ I F V$ & $-\cdot / r \ldots$ & هِ آزمون - ييخيرى & (كروه آزمايش) & \\
\hline$-r / \Delta \cdot r$ & $-r / 99 \wedge$ & $\% \cdots$ & $\cdot / 791$ & $-r / r \Delta \cdot * *$ & يِش آزمون - يس آزمون & \multirow{3}{*}{ (كروهيزه تحصيلى آزمايش) } & \\
\hline$-Y / \Delta r V$ & $-F / \cdot r r$ & $\cdot \cdots$ & $\cdot / r 99$ & $-r / r V Q * *$ & يِش آزمون - ييخيرى & & \\
\hline 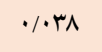 & $-\cdot / \cdot M$ & $-\cdot / 9 V 1$ &.$/ \mathrm{rD}^{2}$ & $-\cdot / \cdot$ ro & 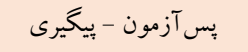 & & \\
\hline
\end{tabular}


اين تحقيقات نشان دادند كه آموزش صلح، تربيت اخلاقى و مهارتهاى

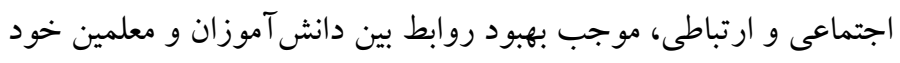

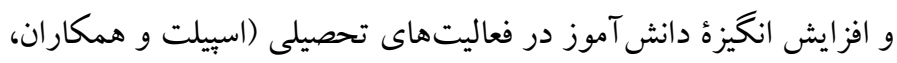

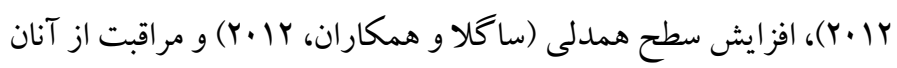
در برابر رفتارهاى برخطر و آسيبهاى اجتماعى (كرشام و همكاران،

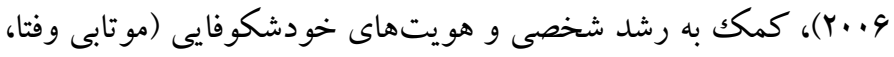

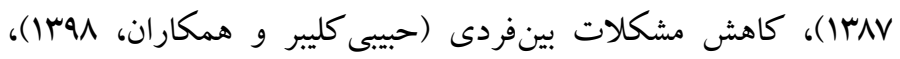

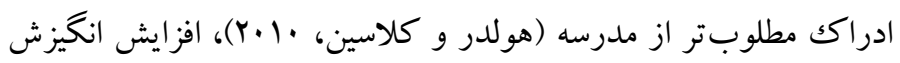
درونى، بيرونى و ساز گارى تحصيلى، بهبود آموزش و ياد گيرى (بهادرى

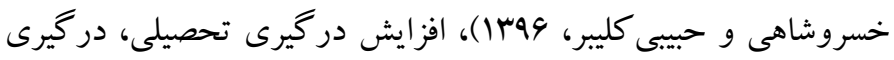

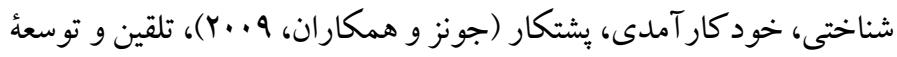

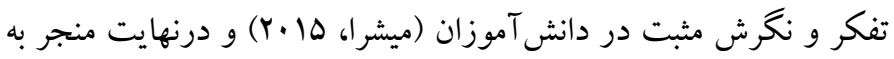

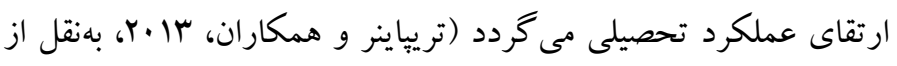
بهادرى خسروشاهى و حبيبى كليبر، 99با؛ يو، دانگك و ليم، 19 إب؛ فروايلند

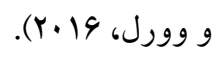

مهارتهاى بين فردى و انخيزش دو مؤلفه تو انمندسازهاى تحصيلى هستند

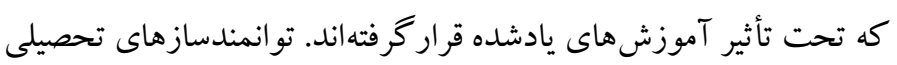

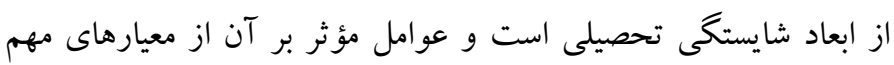

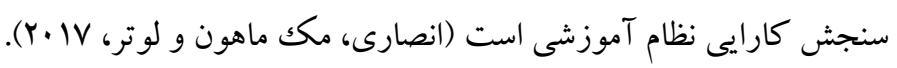

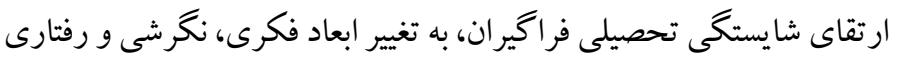

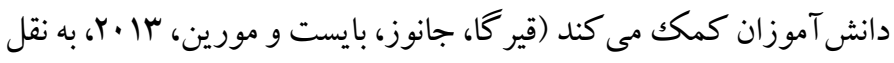

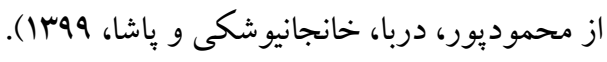
نتيجه حاصل از اين مطالعه را مىتوان از جند بعد تبيين نمود: در درجه

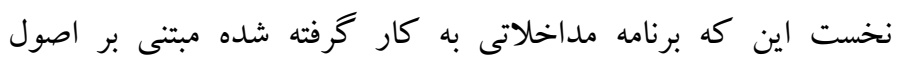

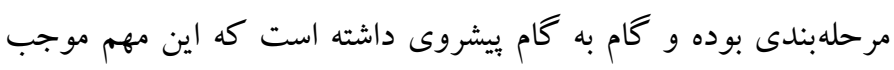

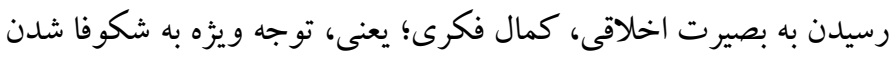
عقل و خرد و بالابردن سطح دانايى و روشن بينى دانش آموزان شده است.

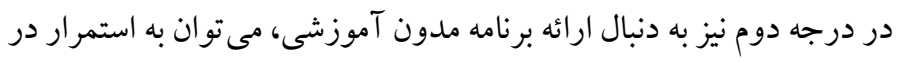

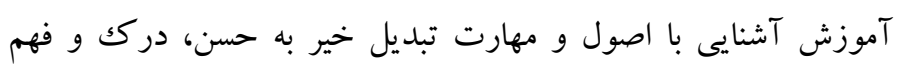
تعارضها و خلق بهترين حسن، مهارت هاى حركت بهسوى آشتى و ساخت

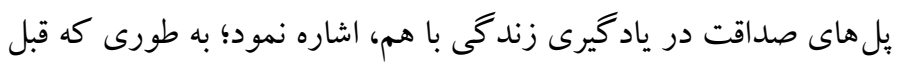

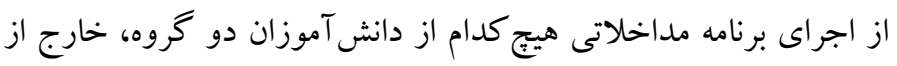

درجدول 9، نتايج آزمون بونفرونى نشان مىدهد تفاوت ميانگين نمرات

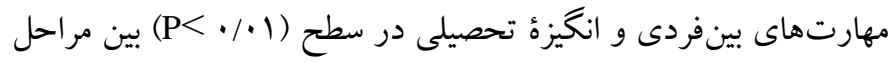

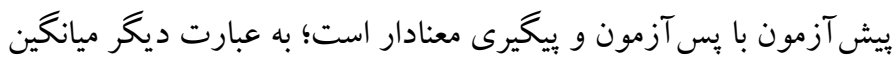

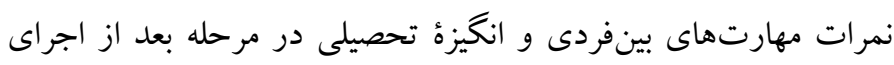

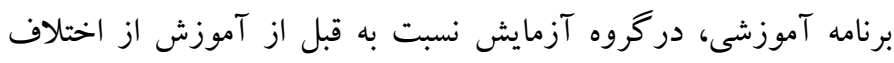

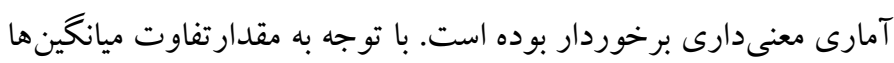

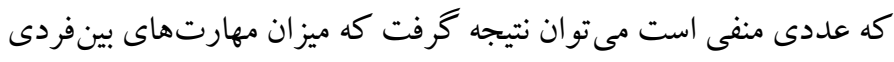

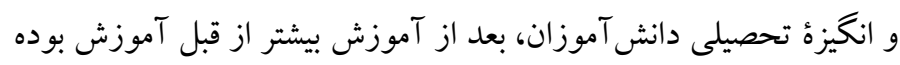

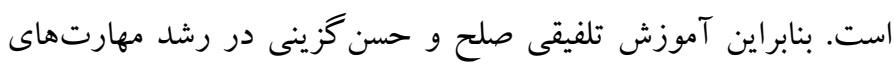
بين فردى و انكيزهُ تحصيلى دانش آموزان، تأثير مثبت داشته است. همرينين

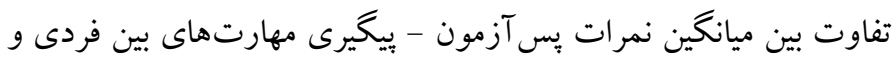

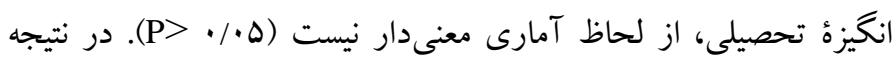

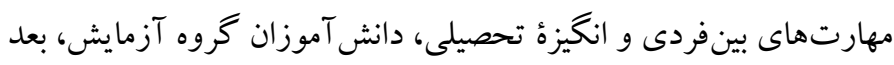

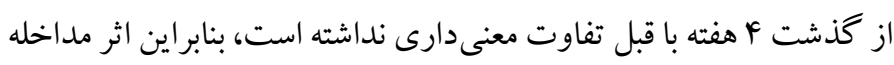

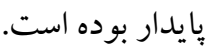

بحث و نتيجه تيرى

اين يثزوهش بهمنظور بررسى اثربخشى آموزش تلفيقى صلح و حسن گزينى

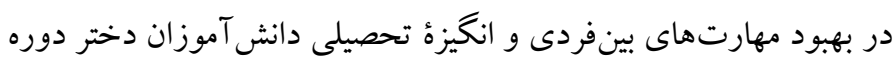

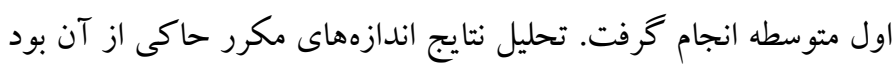
كه اين آموزش در رشد مهارتهاى بين فردى و انخيزه تحصيلى دانش آموزان، تأثير مثبت داشته است.

يُزوهش هاى بسيارى در زمينه تأثير آموزش صلح بر بيشرفت تحصيلى انجام

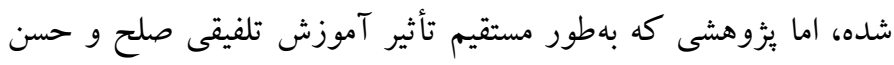

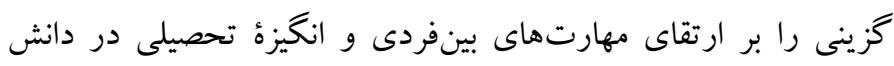
آموزان مورد بررسى قرار دهد، يافت نشد. يافتهاى اين تحقيق به طور غيرمستقيم با نتايج مطالعات انجام شده توسط؛

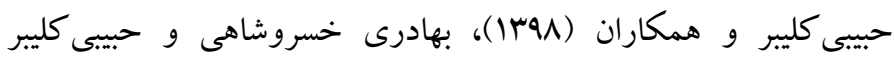

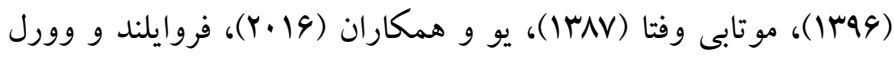
(Y.19)

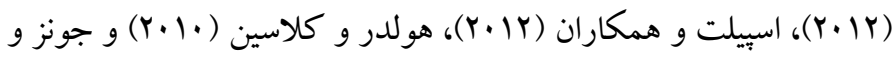

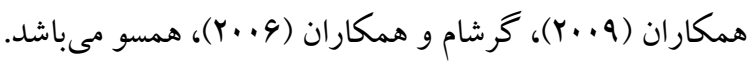


همبستكى در جامعه دارد (مرزوقى، محمدى، شمشيرى و داد گر، هوبا).

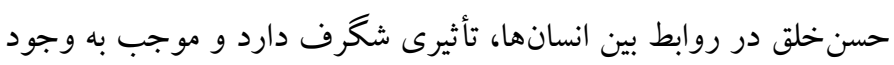

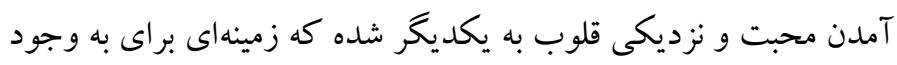

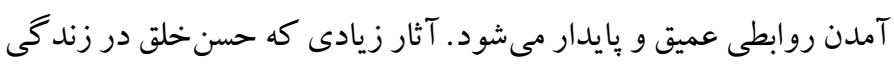

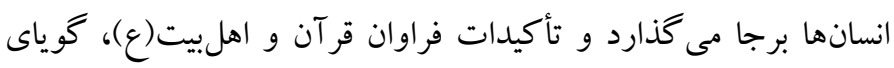

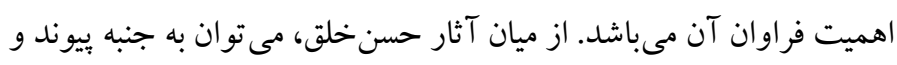

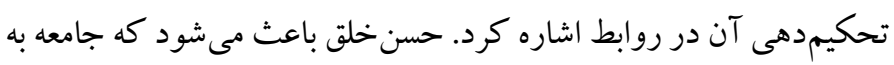

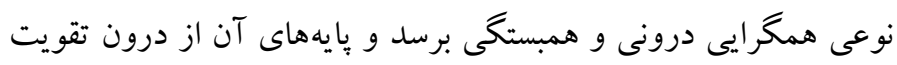
كردد.

مطالعات در رابطه با آموزش صلح و ارزشهاى اخلاقى، آموزش

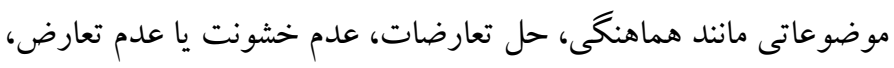

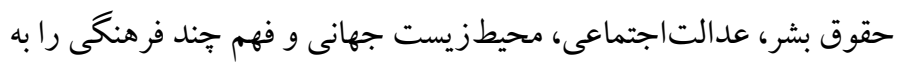

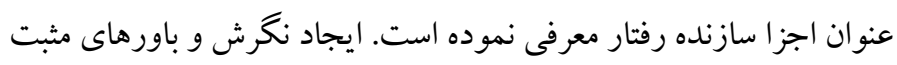

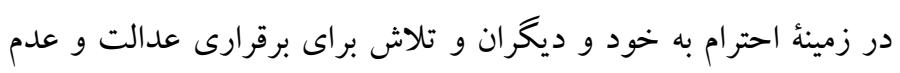
تبعيض از طريق آموزش و يرورش همجنين مبانى و مفاهيم و مناسبات

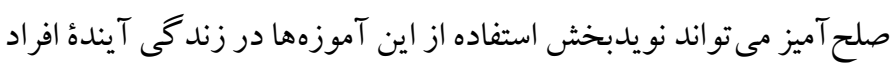

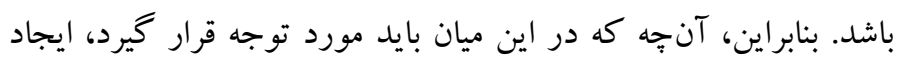

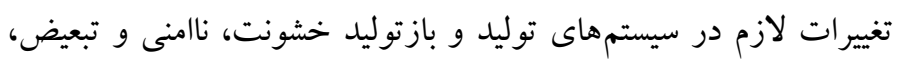

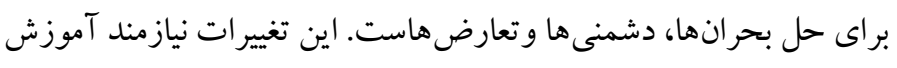

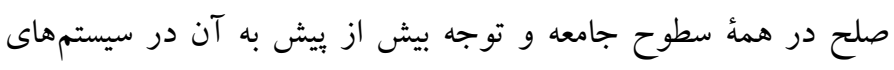

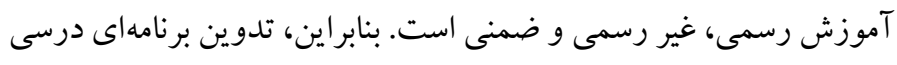

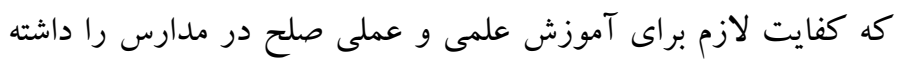
باشد، موضوعى است كه بايد به آن توجهى جدى كرد (مرزوقى و وملى

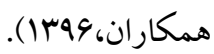

تغييرات اساسى جهانى در راهند و مطمئناً ما در سالهاى آتى شاهد مسائل و مشكلات جهانى مختلفى خواهيم بود. به همين دليل دانش آموزان ما بايد درباره اين مسائل و مشكلات آكاهى داشته باشند و لازمه رسيدن به به به اين آكاهى، آموزش جهانى خواهد بود. هدف آموزش جهانى كسترش در كك

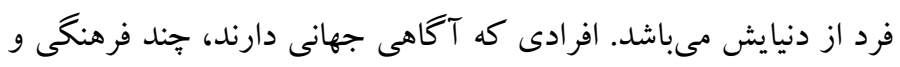
فرامليتى بودن شرايط انسانها و مفهوم صلح را دركك مى كنند. دروس بايد

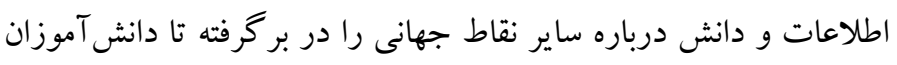

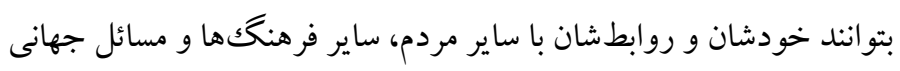

برنامه ارائه شده، به يادگيرى زندگى با هم در صلح و آرامش نبرداخته

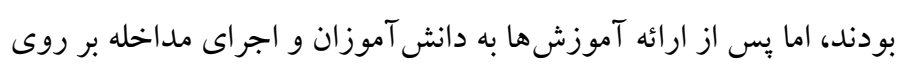

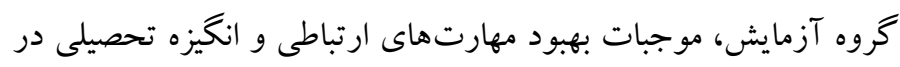
دانش آموزان گروه مداخله فراهم گرديد.

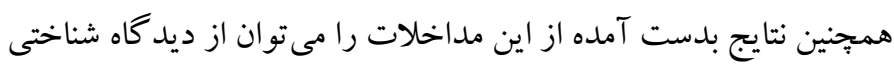

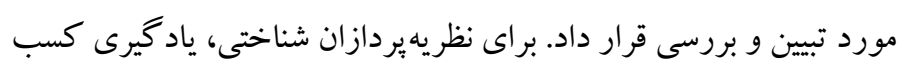

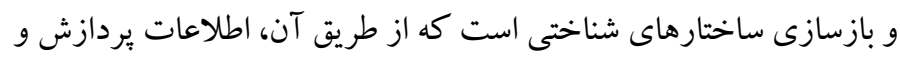

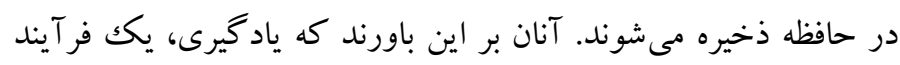

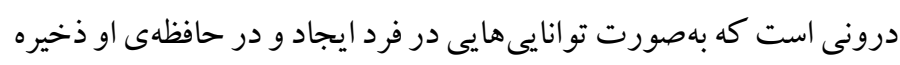
مىشود و هر وقت كه بخواهد، مى تواند آن توانايى ها را مورد استفاده قرار

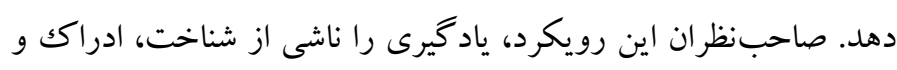

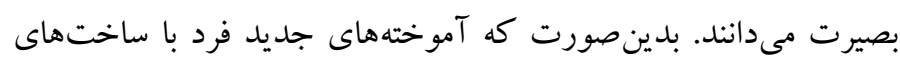
شناختى قبلى او تلفيق مى گردد.

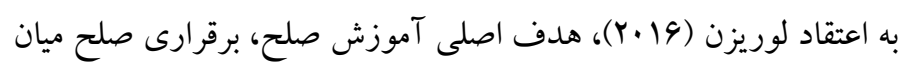

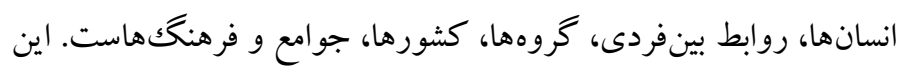

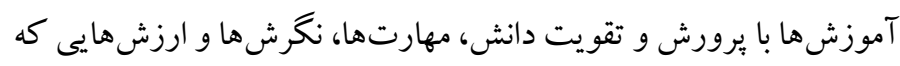

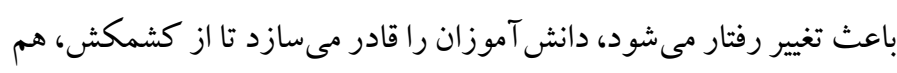

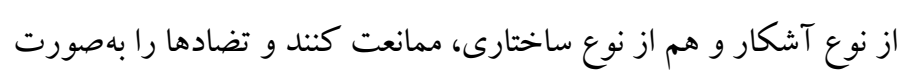
صلح آميز حل كنند، آموزش صلح و تعليم ارزشهاى اخلاق، در زمينه حل

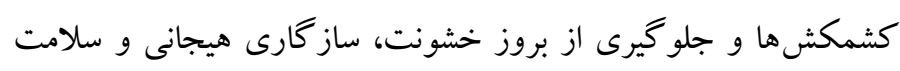

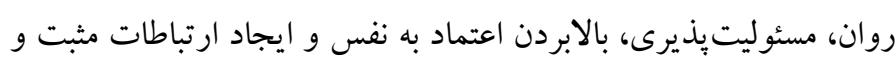

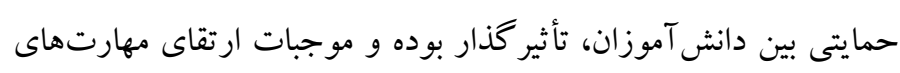

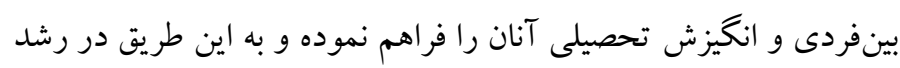
شايستخى تحصيلى دانش آموزان مؤثر بوده است. در دنياى مدرن ييشرفتها و تغييرات حاصل شده در زمينههاى اقتصادى،

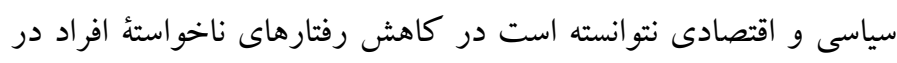

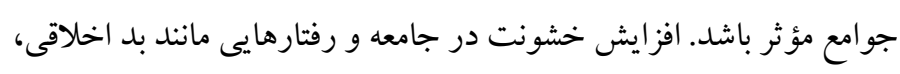

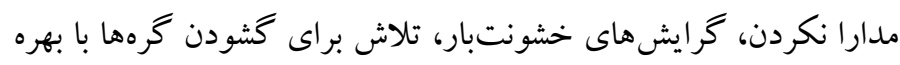

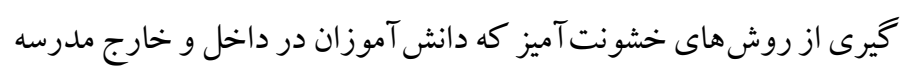

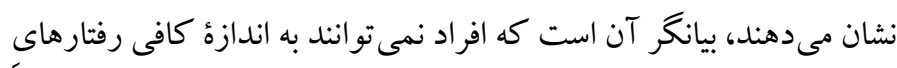

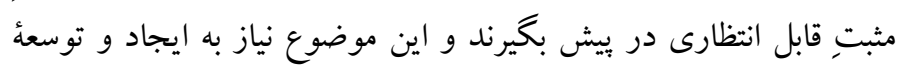

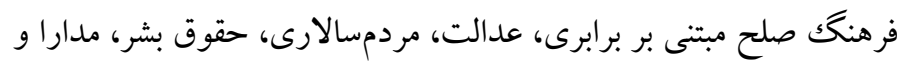


همجون، مؤوليتيذيرى، رفتارهاى ِرخطر احتمالى د دانشآموزان،

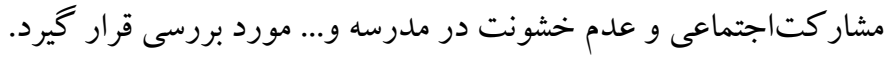

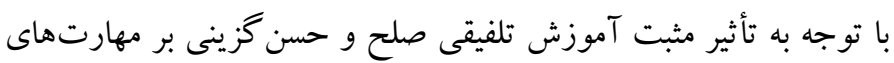

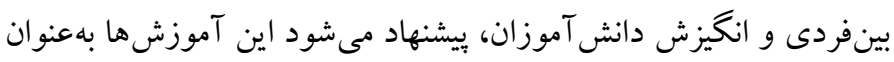

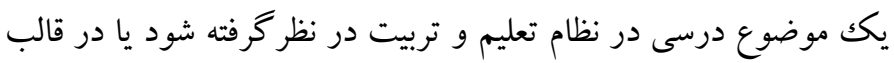
كلاسهاى فوقبرنامه براى دانش آموزان طراحى شود. هم:جنين معلمان و

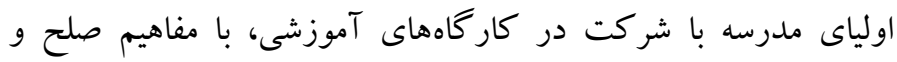
حسن گزينى و اهميت و ضرورت برداختن به آنها در محيط مدرسه و و كلاسهاى درس آشنا شوند. والدين و مربيان با روش هاى متنوع و جذاب، وردئ

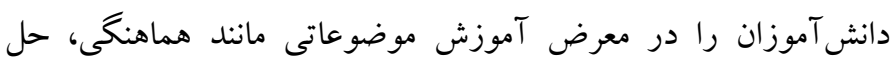
تعارضات، عدم خشونت يا عدم تعارض، حقوقبشر، عدالتاجتماعى،

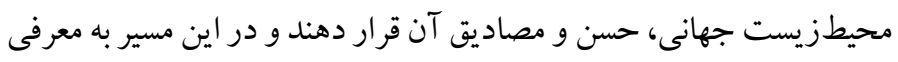

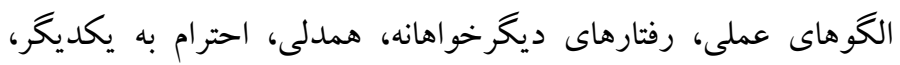
اخلاق شايسته و موارد مرتبط ديخر كه در منابع دينى ما بر آنها تأكيد

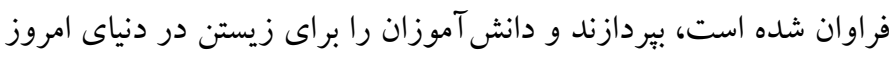
و آينده، آماده نمايند.

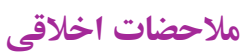

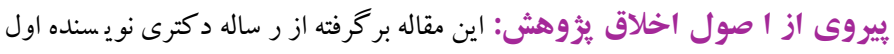

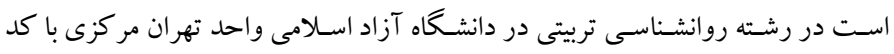

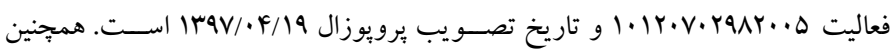

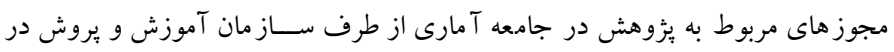
منطقه 19 صادر شده است.

حامى مالى: اين يُزوهش در قالب رساله دكترى و بدون حمايت مالى مىباشد.

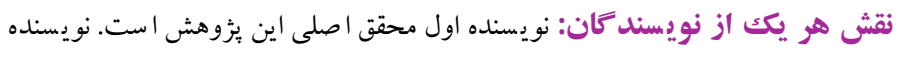
دوم استاد راهنما و نويسنده سوم استاد مشاور مىباشند.

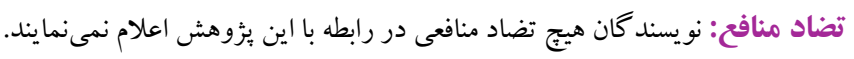

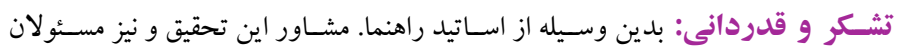

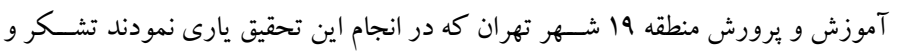
قدردانى مى گردد.
را بهتر در كك نمايند و لازمه رسيدن به اين امر دستيابى به ديد كاهى جهانى مى.باشد. يكى از اهداف آموزش صلح و ارزشهاى اخلاقى، توسعه و ارتقاى

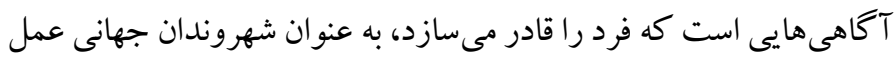

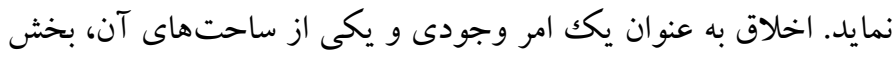

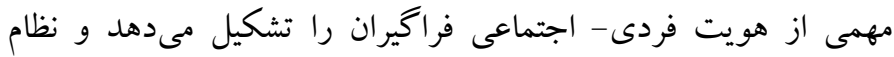
آموزشى نمى تواند و نبايد نسبت به اين جزء از هويت و شخصيت افراد

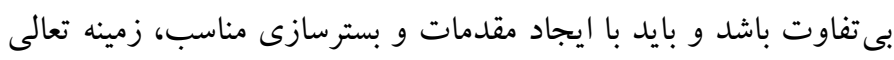

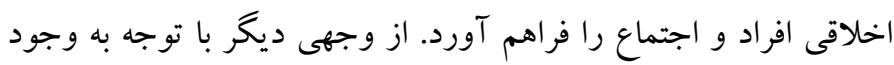
معضلات اخلاقى مختلف در سطح اجتماع و وقوع بحر انهاى اخلاقى در عصركنونى مانند افزايش بزهكارى، تبهكارى، فقر و بىعدالتى و ايجاد

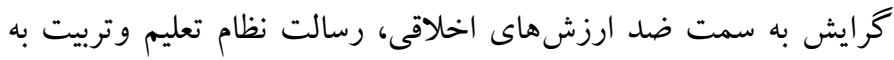
عنو ان يكى از عوامل مهم تأثير گذار برارتقاى سطح اخلاقى افر اد و اجتماع

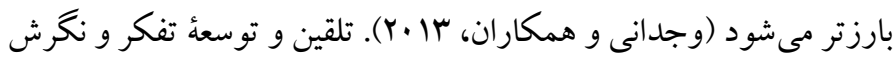
مثبت در دانش آموزان، در آينده موجب دستيابى به اهداف نهايى بهتر و و

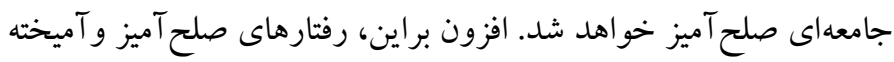

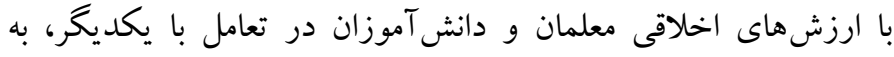

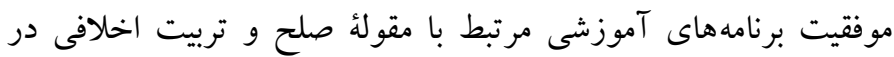

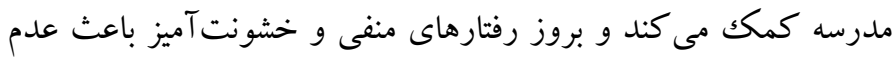
موفقيت مدرسه در اين زمينه مىشود. يُزوهش حاضر با محدوديتهايى نيز روبرو بوده است. از جمله كو تاه و

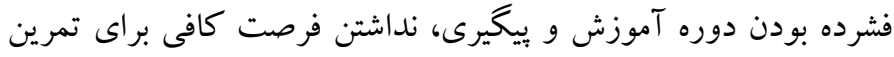

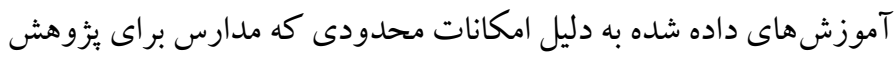

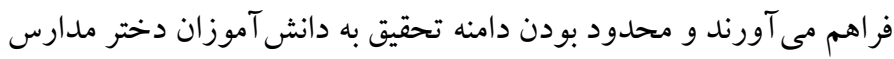
متوسطه اول منطقه 19 تهران كه تعميم نتايج آن را تحت تأثير قرار مى دهدهد. بنابراين بيشنهاد مىشود براى افزايش قدرت تعميميذيرى نتايج، در سطح

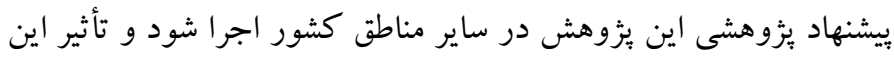

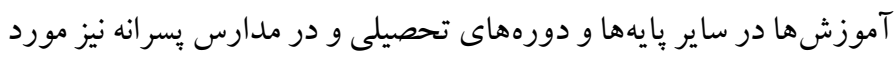

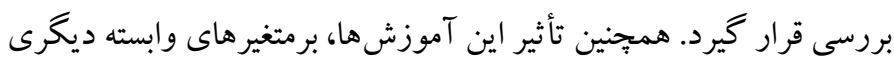




\section{References}

Adabi M, Hajiha A, Khorshidi A. (2020). Designing and evaluating organizational happiness pattern of professors of islamic azad university of tehran branches (combined study). Journal of psychological science, 19(94). 1291-1360. (Persian). [Link]

Anderson, D. (2000). Character Education: Who is Responsible? Journal of Instructional Psychology, 27(3): 139- 159. [Link]

Ansary, N.S., McMahon, T.J.,\& Luthar,S. S. (2017). Trajectories of emotional-behavioral difficulty and academic competence: A 6-year, person-centered, prospective study of affluent suburban adolescents. Development and Psychopathology, 29(1), 215234. [Link]

Bahadori Khosroshahi, Jafar and Habibi-Kalibar, Ramin (1396). The effect of communication skills training on motivation, education and academic adjustment of high school students. Scientific-research journal of education and evaluation, 10 (39), 173-151. [Link]

Baker,J.A. (2006). Contributions of teacher- child relationships to positive school adjustment during elementary School.Journal of School Psychology. 44(3),211-229. [Link]

Bischoff, K. (2016). The Civic Effects of Schools: Theory and Empirics. Theory and Research in Education, 14(1): 91-106. [Link]

Clark, M.H., \& Schroth, C.A. (2010). Examining relationships between academic motivate and personality among college students. Journal of Learning and Individual Differenc, 20(1), 19- 24. [Link]

Dastan,S., Davodo, I., \& Besaknezhad, S. (2014). The effect of stress management training on disappearance, interpersonal problems and dormant adaptation of female students in boarding schools. J Psychol Achiev.; 4(2):205-24. [Link]

Gresham, F.M.,Van, M.B.,\& Cook, C.R. (2006). Social Skills Training for Teaching Replacement Behaviors: Remediating Acquisition Deficits in AtRisk Students. Behavorial Disorders, 31(4):363-77. [Link]

Habibi Kalibar, Ramin; Farid, Abolfazl; Misrabadi, Javad and Bahadori Khosroshahi, Jafar (1398). The effectiveness of social and emotional skills training on improving students' interpersonal relationships. Teaching Strategies in Medical Sciences, (1) 15,128. [Link].
Hajizadeh, Ebrahim and Asghari, Mohammad (1390). Methods and statistical analysis with a view to research methods in biological and health sciences. Tehran: University Jihad Publishing Organization. [Link]

Holder, M. D., \& Klassen, A. (2010). Temperament and Happiness in children. Journal of Happiness Studies. 11(4), 419-439. [Link]

Hossein Mardi, A.A,\& Hossein Mardi, Z. (2015). Prediction of academic achievement based on emotional intelligence and achievement motivation among students of Islamic Azad University of Roudehen branch in 2013. Pajouhan Scientific Journal, 13 (3):15-22. (Persian) [Link]

Kazempour, Ismail; Khalkhali, Ali and Jan Alipour, Reza (1391). The Impact of Peace Education Program on Global Citizen Education. Journal of New Approach in Educational Management, 3 (3) 62-49. [Link].

Kassu, M.B, \& Yimam, J.A. (2016). Multilevel Analysis for Identifying Factors Influencing Academic Achievement of Student in Higher Education Institution: The Case of Wollo University. Journal of Education and Practice,7(13), 17-23. [Link]

Kristjánsson, K. (2016). Aristotelian Character Education. London: Routledge. [Link]

Larry, Narcissus; Hejazi, Goddess; Ejei, Javad and Jokar, Bahram (1398). Teachers' perception of the factors affecting the teacher-student relationship: Phenomenological analysis. Journal of Educational Innovations, (18) 70, 80-53. [Link].

Lauritzen, S.M. (2016).Building peace through education in a post-conflict environment: A case study exploring perceptions of best practices International. Journal of Educational Development.51:77-83. [Link]

Levett Jones,T., Lathlean, J., Higgins, I., \& McMillan, M. (2009). Staff student relationships and their impact on nursing students' belongingness and learning. Journal of advanced nursing, 65(2), 316-24. [Link]

Mishra L. (2015). Implementing Peace Education in Secondary Schools of Odisha: Perception of Stake Holders. Sakarya University Journal of Education 5(2):47-54. [Link]

Mahmoudpour, Abdul Basit; Derba, Mohammad; Khanjaniushki; Sahar and Pasha, Shima (1399). Predicting academic competence based on parenting styles, perceived self-efficacy, and student emotion regulation. Journal of Psychological Sciences, 19 (11), 1124-1115. [Link]. 
Mousavi, worthy; Abolmaali, Khadijeh and Mirhashemi, Malik (1396). The mediating role of academic emotions in the relationship between constructiveoriented learning environment and academic competence in high school girls in Tehran. Journal of Applied Psychological Research, 8 (2), 95-72. [Link].

Mousavi, Seyedeh Shayesteh and Abolmaali, Khadijeh (1397). The role of academic identity and academic excitement in predicting the academic competence of female high school students. Quarterly Journal of New Psychological Research, 13 (52), 252-231. [Link].

Marzooqi, Rahmatullah; Mohammadi, Mehdi; Shamshiri, Babak and Dadgar, Homayoun (1396). Developing a Peace Curriculum in Higher Education: A Qualitative Study. Journal of Education Strategies in Medical Sciences, 10 (5), 396-384. [Link].

Ryan‘R.M. (1995). Psychological needs and the facilitation of integrative processes. Journal of personality, 63(3), 397-427. [Link]

Riley.P. (2009). An adult attachment perspective on the student- teacher relationship \& classroom management difficulties. Teaching and teacher education, 25(5), 626-635. [Link]

Rowell, L. Hong, E. (2013). Academic Motivation: Concepts, Strategies, and Counseling Approaches. Professional School Counseling, 16(3), 158-171. [Link]

Steenburger, B. (2004).The Art and Science of the Brief Psychotherapies: American Psychiatric Press, Inc. [Link]

Spilt, J.L., Hughes,J.N., Wu, J.y., \&Kwok, O.M. (2012). Dynamics of teacher-student relationships: Stability and change across elementary school and the influence on children s' academic success. Child development, 83(4),1180-1195. [Link]

Schunk, D.H., Pintrich, J.R., \& Meece, P.R. (2012). Motivation in education: Theory, research and applications. New York, NY: Pearson Higher ED. [Link]

Tajeri, B. (2016).Effectiveness of problem solving training on interpersonal sensitivity \& aggression in students. J Sch Psychol.5(3):39-55. [Link]

Uko, E.S., Igbineweka P.O, \& Odigwe F.N. (2015). Promoting Peace Education for Behavioral Changes in Public Secondary Schools in Calabar Municipality Council Area, Cross River State, Nigeria. Journal of Education and Practice 2015; 6 (23):144 - 149. [Link]
Vojdani, F., Imani, M., Akbarian, R., \& Sadeghzade Ghamsari. (2013). the nature of moral education from the point of view be Individual or collective from the perspective of Allame Tabatabai. Research on Islamic Education Issues, 21(1): 11-23[In Persian]. [Link]

You,S., Dang, M., \& Lim, S.A. (2016). Effects of student perceptions of teachers' motivational behavior on reading, English and mathematics achievement: The mediating role of domain specific efficacy-self and intrinsic motivation. Child \& Youth Care Forum, 45(2), 221-240. [Link] 